\title{
The role of contact angle and pore width on pore condensation and freezing
}

\author{
Robert O. David ${ }^{1, a}$, Jonas Fahrni ${ }^{2, b}$, Claudia Marcolli ${ }^{1}$, Fabian Mahrt ${ }^{1, \mathrm{c}}$, Dominik Brühwiler ${ }^{2}$, and Zamin A. Kanji ${ }^{1}$ \\ ${ }^{1}$ Institute for Atmospheric and Climate Science, ETH Zürich, 8092 Zurich, Switzerland \\ ${ }^{2}$ Institute of Chemistry and Biotechnology, Zürich University of Applied Sciences (ZHAW), 8820 Wädenswil, Switzerland \\ ${ }^{a}$ now at: Department of Geosciences, University of Oslo, Oslo, 0315, Norway \\ b now at: RISE Processum AB, Bioeconomy and Health, Örnsköldsvik, 891 22, Sweden \\ ${ }^{\mathrm{c}}$ now at: Department of Chemistry, University of British Columbia, 2036 Main Mall, Vancouver, BC, V6T 1Z1, Canada
}

Correspondence: Robert O. David (r.o.david@geo.uio.no) and Zamin A. Kanji (zamin.kanji@env.ethz.ch)

Received: 4 November 2019 - Discussion started: 21 November 2019

Revised: 15 June 2020 - Accepted: 30 June 2020 - Published: 12 August 2020

\begin{abstract}
It has recently been shown that pore condensation and freezing (PCF) is a mechanism responsible for ice formation under cirrus cloud conditions. PCF is defined as the condensation of liquid water in narrow capillaries below water saturation due to the inverse Kelvin effect, followed by either heterogeneous or homogeneous nucleation depending on the temperature regime and presence of an ice-nucleating active site. By using sol-gel synthesized silica with well-defined pore diameters, morphology and distinct chemical surfacefunctionalization, the role of the water-silica contact angle and pore width on PCF is investigated. We find that for the pore diameters $(2.2-9.2 \mathrm{~nm})$ and water contact angles (15$78^{\circ}$ ) covered in this study, our results reveal that the water contact angle plays an important role in predicting the humidity required for pore filling, while the pore diameter determines the ability of pore water to freeze. For $T>235 \mathrm{~K}$ and below water saturation, pore diameters and water contact angles were not able to predict the freezing ability of the particles, suggesting an absence of active sites; thus ice nucleation did not proceed via a PCF mechanism. Rather, the ice-nucleating ability of the particles depended solely on chemical functionalization. Therefore, parameterizations for the ice-nucleating abilities of particles in cirrus conditions should differ from parameterizations at mixed-phase clouds conditions. Our results support PCF as the atmospherically relevant ice nucleation mechanism below water saturation when porous surfaces are encountered in the troposphere.
\end{abstract}

\section{Introduction}

In the Earth's atmosphere, ice crystals are important for precipitation formation (Mülmenstädt et al., 2015), cloud lifetime, and radiative properties and ultimately modulate climate (McFarquhar et al., 2017; Seinfeld et al., 2016). Understanding the formation of ice crystals is therefore essential to accurately predict cloud properties and thus future climate. The freezing temperature of pure water droplets is approximately $235 \mathrm{~K}$, known as the homogeneous freezing temperature (HFT). However, ice formation is also observed at temperature $T>$ HFT or below water saturation. At $T>$ HFT ice formation takes place heterogeneously and is aided by the presence of a foreign substance (Fletcher, 1969; Kaufmann et al., 2017; Kiselev et al., 2017; Vali et al., 2015), which lowers the energy barrier required for the homogeneous nucleation of ice. Below water saturation, ice nucleation is conventionally defined as deposition nucleation - the direct transition from water vapor to the ice phase without an intermediate liquid water phase (Pruppacher and Klett, 1997; Vali et al., 2015). However, it has been shown that ice nucleation below water saturation occurs in the presence of cracks and steps (Campbell et al., 2017; Christenson, 2013; David et al., 2019; Fukuta, 1966; Higuchi and Fukuta, 1966; Kovács et al., 2012; Kovács and Christenson, 2012; Pach and Verdaguer, 2019; Wang et al., 2016) and has subsequently been termed pore condensation and freezing (PCF; Campbell and Christenson, 2018; David et al., 2019; Marcolli, 2014; Pach and Verdaguer, 2019; Umo et al., 2019; Vali et al., 2015; Wagner et al., 
2016). PCF occurs when liquid water, which can exist in narrow pores, cracks, cavities or capillaries (hereafter referred to as pores) below ambient water saturation, freezes. Due to the negative or concave curvature of water in confinements, the vapor pressure required for condensation to occur in a pore compared to a flat/bulk water surface can be predicted by the inverse version of the Kelvin equation given as

$$
\frac{p_{\mathrm{lc}}}{p_{1}}=\exp \left[\frac{-4 \gamma(T) v_{1}(T)}{\frac{D}{\cos \theta} R T}\right],
$$

where $p_{\mathrm{lc}}$ is the vapor pressure of water over a concave surface, $p_{1}$ is the vapor pressure of water over a flat surface and $\frac{p_{\mathrm{lc}}}{p_{1}}$ denotes the saturation ratio with respect to water, while $\gamma(T)$ is the temperature-dependent surface tension of the water-vapor interface, $v_{1}(T)$ is the molar volume of water as a function of temperature, $D$ is the pore diameter, $R$ is the gas constant and $T$ is the temperature in Kelvin. $\theta$ is the contact angle of water on the (pore) material or the wettability of the material, where $\theta=0^{\circ}(\cos \theta=1)$ denotes a perfectly wettable surface, whereas higher water contact angles denote less hydrophilic surfaces (Lohmann et al., 2016). As deduced from Eq. (1), the relative humidity with respect to water $\left(\mathrm{RH}_{\mathrm{w}}\right)$ required for a pore to fill depends on the pore diameter and the water contact angle of the pore surface. As such, at a given water contact angle, a narrower pore will fill at a lower $\mathrm{RH}_{\mathrm{w}}$ than a wider pore. Conversely, for a fixed pore diameter, the higher the contact angle of water on the pore surface, the higher the $\mathrm{RH}_{\mathrm{w}}$ required for pore filling.

Once the pore is filled, the water can freeze either homogeneously or heterogeneously depending on the temperature regime or the presence of a site, as long as the pore is wide enough to host the critical ice germ (Campbell et al., 2017; Campbell and Christenson, 2018; David et al., 2019; Koop, 2017; Marcolli, 2014). In order for the phase transition from supercooled water to ice to occur, classical nucleation theory (CNT) predicts that a large enough cluster of water molecules, known as a germ, must organize into ice before the entire water volume can freeze (Fletcher, 1962; Lohmann et al., 2016; Pruppacher and Klett, 1997). The radius of this critical ice germ $\left(r_{\mathrm{c}}\right)$ can be calculated as

$r_{\mathrm{c}}=\frac{2 \sigma_{\mathrm{iw}} v_{\mathrm{ice}}}{R T \ln \frac{p_{\mathrm{w}}}{p_{\mathrm{i}}}}$,

where $\sigma_{\mathrm{iw}}$ is the interfacial energy between the ice and water interface, $v_{\text {ice }}$ is the approximate volume of bulk ice, and $\frac{p_{\mathrm{w}}}{p_{\mathrm{i}}}$ is the ratios of the equilibrium vapor pressures over water and ice. Additionally, it has been shown that even down to extreme supercooling $(T<200 \mathrm{~K})$, a quasi-liquid layer of water is present along the pore wall (Jähnert et al., 2008; Marcolli, 2014; Moore et al., 2010; Schreiber et al., 2001). The width of the quasi-liquid layer has been shown to depend on temperature and surface chemistry, but the exact thickness of the layer varies greatly between different observational techniques and molecular dynamic studies (Bartels-Rausch et al., 2014). Nevertheless, the thickness of the quasi-liquid layer can be parameterized by fitting the measured melting point depressions of ice in pores to a modified version of the Gibbs-Thomson equation and has been shown to vary between one and two monolayers thick for the pore diameters and across the temperature range investigated in this study (Findenegg et al., 2008; Jähnert et al., 2008; Marcolli, 2014; Schreiber et al., 2001; Wang et al., 2019). When accounting for the quasi-liquid layer thickness, assumed as $t=0.38 \mathrm{~nm}$ (Schreiber et al., 2001), the diameter of a pore capable of hosting ice $\left(D_{\mathrm{p}}\right)$ can be expressed as

$D_{\mathrm{p}} \geq 2 r_{\mathrm{c}}+2 t$.

Indeed, Marcolli (2014) reported that $D_{\mathrm{p}}$ is a good predictor for ice forming in porous silica particles. However, once pore ice is formed, it must grow out of the pore, i.e., into the unconfined vapor region. Based on CNT, the ice growing out of the pore needs to be supercritical with respect to the vapor phase. The energy barrier for nucleation in the vapor phase is significantly higher than that in water. This increase in energy barrier comes from the need to replace $\sigma_{\mathrm{iw}}$ with the interfacial energy between ice and vapor $\left(\sigma_{\text {iv }}\right)$ in Eq. (2), which is approximately a factor of 4.8 larger than $\sigma_{\text {iw }}$ at 236 K (Cooper, 1974; Ickes et al., 2015; Ketcham and Hobbs, 1969). Additionally, as the ice growing out of the pore experiences an environment that is subsaturated with respect to water, $\frac{p_{\mathrm{w}}}{p_{\mathrm{i}}}$ in Eq. (2) must be replaced by the ice saturation ratio $\left(S_{\mathrm{i}}\right)$, which is smaller than $\frac{p_{\mathrm{W}}}{p_{\mathrm{i}}}$. Therefore, the critical radius for ice growth out of the pore is much larger than that of the critical radius in the pore, necessitating a substantial increase in $S_{\mathrm{i}}$ for ice to be able to grow out of a pore (David et al., 2019; Koop, 2017). Indeed, Campbell et al. (2017) and Campbell and Christenson (2018) showed that an increase in supersaturation is required for crystallites formed in wedgeshaped pores to emerge into the unconfined vapor region, which they interpreted as a second energy barrier for ice growth out of pores. In addition, molecular dynamic simulations (MDS) conducted by Page and Sear (2006) showed that protein crystal nucleation out of single pores is maximized when the pore width is close to the critical nucleus size in order to minimize the energy for pore filling and for the crystal growth out of the pore. Conversely, mesoporous silica with closely spaced cylindrical pores did not reveal any inhibition of ice growth out of pores (David et al., 2019). This result is supported through MDS- and CNT-based calculations revealing that an arrangement of several subcritical cylindrical pores closely spaced together greatly decreases $S_{\mathrm{i}}$ required for ice growth out of pores due to pore-ice bridging across adjacent pores (David et al., 2019).

Although there is strong evidence that pores are responsible for ice nucleation below water saturation, the ability of PCF to predict ice nucleation as a function of pore width and water contact angle has not been shown systematically. For 
example, in an earlier study we showed that pores were responsible for the observed ice nucleation of synthesized silica and NX-illite particles and that the humidities required for ice formation were consistent with PCF (David et al., 2019). Here we present results from synthesized porous silica with well-defined pore diameters, geometry and water contact angles to better understand the PCF mechanism and its predictive capability for ice nucleation at water subsaturated conditions.

\section{Methods}

\subsection{Particle synthesis}

\subsubsection{Synthesis of MCM-41 submicron mesoporous silica particles}

The MCM-41 (see Fig. 1a and b) particles were synthesized following Beck et al. (1992), where: $\mathrm{NH}_{4} \mathrm{OH}(121 \mathrm{~mL}$, $28 \%$, Sigma-Aldrich), deionized water $(300 \mathrm{~mL})$ and ethanol (500 mL, 99.8\%, Sigma-Aldrich) were stirred for $5 \mathrm{~min}$ in a $1 \mathrm{~L}$ polypropylene beaker. For the synthesis of materials with 2.8 or $3.3 \mathrm{~nm}$ pores, $\mathrm{C}_{16} \mathrm{TMABr}$ (hexadecyltrimethylammonium bromide, $1.74 \mathrm{~g}, 99 \%$, Acros) was subsequently added and stirred for $15 \mathrm{~min}$ before TEOS (tetraethoxysilane, $4.5 \mathrm{~mL}, 20.2 \mathrm{mmol}, 98 \%$, Sigma-Aldrich) was quickly dropped into the reaction mixture. For $2.5 \mathrm{~nm}$ pores, a mixture of $\mathrm{C}_{16} \mathrm{TMABr}(0.871 \mathrm{~g}, 99 \%)$ and $\mathrm{C}_{14} \mathrm{TMABr}$ (tetradecyltrimethylammonium bromide, $0.804 \mathrm{~g}$, $99 \%$, SigmaAldrich) was used. After a few minutes, silica started to precipitate. The reaction was stirred at room temperature for $2 \mathrm{~h}$ before filtering (Sartorius ${ }^{\circledR}$ 393). The filter cake was subsequently washed twice with $50 \mathrm{~mL}$ of deionized water, dried at $T=80^{\circ} \mathrm{C}$ for approximately $1 \mathrm{~h}$ and finally ground in methanol for $3 \mathrm{~min}$. To obtain $3.3 \mathrm{~nm}$ pores, the dried particles were transferred into a Teflon-lined acid digestion vessel (Parr 4748), suspended in deionized water $(80 \mathrm{~mL})$, aged $\left(80^{\circ} \mathrm{C}, 24 \mathrm{~h}\right)$, subsequently filtered (Sartorius ${ }^{\circledR} 393$ ), dried and ground in methanol (99\%, Sigma-Aldrich). After drying again $\left(80^{\circ} \mathrm{C}, \geq 1 \mathrm{~h}\right)$, the particles were calcined at $550{ }^{\circ} \mathrm{C}$ for $12 \mathrm{~h}$.

\subsubsection{Synthesis of SBA-15 submicron mesoporous silica particles}

To obtain larger pore diameters $(\sim 9 \mathrm{~nm})$, SBA-15 particles (see Fig. 1c and d) were synthesized similarly to Linton et al. (2009b) where Pluronic ${ }^{\circledR}$ P104 (1.25 g, BASF) was dissolved under vigorous stirring in a hydrochloric acid solution $\left(200 \mathrm{~mL}, 1.6 \mathrm{~mol} \mathrm{~L}^{-1}\right.$ ) at $60^{\circ} \mathrm{C}$ and TMOS (tetramethoxysilane, $8 \mathrm{~mL}, 99 \%$, Sigma-Aldrich) was added quickly under vigorous stirring. After $1 \mathrm{~min}$ (approximate hydrolysis time, Linton et al., 2009a) the stirring rate was lowered to moderate stirring. After another $1 \mathrm{~min}$, the reaction mixture was diluted with a hydrochloric acid solution $\left(200 \mathrm{~mL}, 1.6 \mathrm{~mol} \mathrm{~L}^{-1}\right)$,

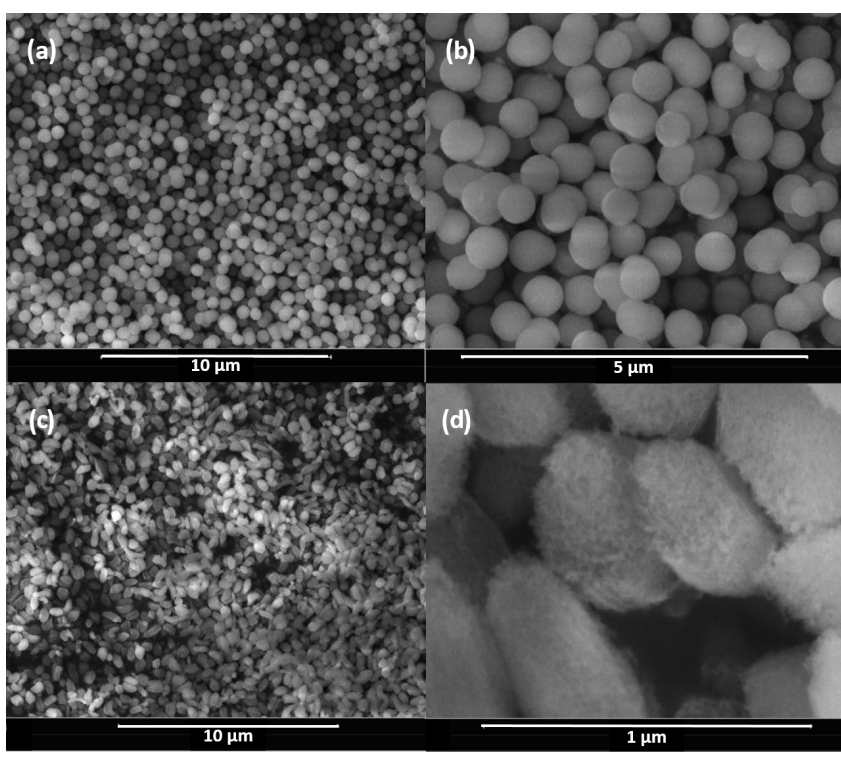

Figure 1. Scanning election microscopy images of (a, b) $2.8 \mathrm{H} 2$ as an example of MCM-41 particles and (c, d) $9.0 \mathrm{M} 2$ as an example of SBA-15 particles.

leading to precipitation of the silica. The reaction mixture was further stirred at $60^{\circ} \mathrm{C}$ for $24 \mathrm{~h}$. The resulting suspension was centrifuged and washed with deionized water $(200 \mathrm{~mL})$ twice, and the product was transferred to the Teflon-lined acid digestion vessel. The wet particles were dispersed in deionized water $(60 \mathrm{~mL})$, and the $\mathrm{pH}$ was adjusted to 9 by the addition of $\mathrm{NH}_{4} \mathrm{OH}(1.05 \mathrm{~mL}, 28 \%)$. The mixture was aged in quiescent conditions at $80^{\circ} \mathrm{C}$ for $15 \mathrm{~h}$. The suspension was centrifuged and washed with deionized water $(200 \mathrm{~mL})$ twice and once with ethanol $(70 \%)$. The white powder was dried $\left(80^{\circ} \mathrm{C}, \geq 1 \mathrm{~h}\right)$ before it was ground in methanol $(99 \%)$ for $3 \mathrm{~min}$. After drying again $\left(80^{\circ} \mathrm{C}, \geq 1 \mathrm{~h}\right)$, the particles were calcined at $550^{\circ} \mathrm{C}$ for $12 \mathrm{~h}$.

\subsubsection{Particle functionalization}

In order to investigate the impact of water contact angle on the ability of porous particles to nucleate ice via PCF, particles of similar pore diameters were functionalized with trimethyl and hydroxyl groups after calcination. We will focus on ice nucleation experiments with particles functionalized with trimethyl and hydroxyl groups rather than just calcined ones, as their water contact angle was observed to change with aging in air (Muster et al., 2001). A batch of $2.8 \mathrm{~nm}$ pore samples was calcined at $550^{\circ} \mathrm{C}$ and then separated into three parts, with one part unmodified, one part hydroxylated and the remaining part methylated. A summary of the particles investigated in this study is provided in Table 1. Hydroxylation and methylation were conducted as follows:

- Silanol surface (hydroxylation): a calcined sample $(1.0 \mathrm{~g})$ was suspended in toluene $(200 \mathrm{~mL})$ and heated 
to $60^{\circ} \mathrm{C}$ before a calculated amount of water was added (Eq. A1 of Appendix A1) in order to achieve a concentration of 4.6 silanol groups $\mathrm{nm}^{-2}$ (Zhuravlev, 2000). The particles were then suspended for $60 \mathrm{~min}$ through vigorous stirring and occasional sonication, before the suspension was filtered and washed with deionized water $(80 \mathrm{~mL})$ and dried $\left(120^{\circ} \mathrm{C}, 20 \mathrm{mbar}\right)$ overnight.

- Alkyl surface (trimethylation): a calcined sample (1.0 g) was suspended in toluene $\left(200 \mathrm{~mL}\right.$ at $\left.60^{\circ} \mathrm{C}\right)$ before a 2-fold excess of organosilane (trimethylchlorosilane, $99 \%$, Sigma-Aldrich) as calculated using Eq. (A2) (Appendix A1) was added. The reaction was run for $3 \mathrm{~h}$, and then the suspension was filtered and washed with toluene $(50 \mathrm{~mL})$, ethanol $(50 \mathrm{~mL})$ and water $(50 \mathrm{~mL})$. The particles were then dried $\left(120^{\circ} \mathrm{C}\right.$, 20 mbar) overnight.

\subsection{Particle characterization}

\subsubsection{Nitrogen adsorption and calculation of pore size distribution}

Particle surface area $\left(S_{\mathrm{BET}}\right)$ and pore diameters were determined by nitrogen adsorption (Quantachrome, NOVA $3000 \mathrm{e})$. The nitrogen isotherms were obtained by measuring $>10 \mathrm{~m}^{2}$ of dried $\left(80^{\circ} \mathrm{C}\right)$ sample, and the $S_{\text {BET }}$ was obtained from the relative pressure range where multilayer adsorption takes place (0.05-0.30) and applying the Brunauer, Emmett and Teller (BET) gas adsorption theory (Brunauer et al., $1938)$. The average pore diameter $\left(d_{\mathrm{DFT}}\right)$ was obtained using the NLDFT (nonlocal density functional theory) method (Landers et al., 2013) applied to the $\mathrm{N}_{2}$ sorption measurements.

\subsubsection{DRIFTS}

Diffuse reflectance infrared Fourier transform spectroscopy (DRIFTS) was used to characterize the functionalized particles and estimate the concentration of hydroxyl and methyl groups on the silica particles. The samples were prepared by combining $6 \mathrm{mg}$ of dried sample $\left(80^{\circ} \mathrm{C},>1 \mathrm{~h}\right)$ with $194 \mathrm{mg}$ of dry potassium bromide $(\mathrm{KBr})$ to produce a $3 \%$ $(w / w)$ mixture. The mixture was ground vigorously for over a minute (Hamadeh et al., 1984) before being filled in the sample holder, where the sample was flattened with a spatula. A scan resolution of $4 \mathrm{~cm}^{-1}$ was chosen, and background scans with pure $\mathrm{KBr}$ were performed; each sample was corrected accordingly. The mixtures were scanned immediately after grinding to avoid the adsorption of water vapor. The background-corrected scans were averaged and then normalized to the BET surface area of the sample instead of using the traditional method of normalizing based on the $\mathrm{Si}-$ $\mathrm{O}$ asymmetric stretching peak in the vicinity of $1100 \mathrm{~cm}^{-1}$ (Muster et al., 2001). Normalization to the BET surface is more appropriate considering the porous nature of the samples.

\subsubsection{Water sorption and water contact angle derivation}

Water sorption isotherms were obtained using dynamic vapor sorption (DVS; TA Instruments, VTI-SA+), where the water uptake is determined gravimetrically. Each isotherm was obtained using approximately $10 \mathrm{mg}$ of sample dried at $120^{\circ} \mathrm{C}$ in a pure nitrogen atmosphere for $1 \mathrm{~h}$ before the reference mass was determined in order to evaporate any preadsorbed water. The DVS cell was then cooled to the temperature $\left(T=25^{\circ} \mathrm{C}\right)$ at which the sorption measurements were performed. The adsorption isotherms were obtained by continuously measuring the sample mass while increasing the humidity from $0 \%$ to $90 \%$ in steps of $5 \% \mathrm{RH}_{\mathrm{w}}$. The water uptake reported here denotes quasi equilibrium values at each $\mathrm{RH}_{\mathrm{W}}$ step defined as a mass change rate less than $0.008 \%$ over the course of $5 \mathrm{~min}$. The water contact angle of the sample surface was then determined from the sorption isotherm using the Cohan-Kelvin equation (Kocherbitov and Alfredsson, 2007):

$r_{\mathrm{nldft}}-t_{\mathrm{ads}}=-\frac{2 \gamma(T) \cos (\theta) v_{1}(T)}{R T \ln \left(p / p_{0}\right)}$.

Here $t_{\mathrm{ads}}$ is the statistical thickness of adsorbed water, $r_{\mathrm{nldft}}$ is the pore radius as determined by $\operatorname{NLDFT}\left(d_{\mathrm{DFT}} / 2\right)$, and $p / p_{0}$ is the water saturation ratio or $\mathrm{RH}_{\mathrm{w}} / 100$. The statistical thickness in cylindrical pores is calculated by subtracting the volume of the adsorbate ( $V_{\text {ads }}$ ) from the full pore volume $\left(V_{\text {tot }}\right)$ and can be rewritten as

$r_{\mathrm{nldft}}-t_{\mathrm{ads}}=\frac{r_{\mathrm{nldft}}}{\sqrt{\frac{V_{\mathrm{tot}}}{V_{\mathrm{tot}}-V_{\mathrm{ads}}}}}$.

By substituting Eq. (5) into Eq. (4), the Cohan-Kelvin equation for cylindrical pores can be written as

$r_{\mathrm{nldft}}=-\sqrt{\frac{V_{\mathrm{tot}}}{V_{\mathrm{tot}}-V_{\mathrm{ads}}}} \cdot \frac{2 \gamma(T) \cos (\theta) v_{\mathrm{l}}(T)}{R T \ln \left(p / p_{0}\right)}$.

And when solving for $\theta$ becomes

$\theta=\arccos \left(\frac{r_{\text {nldft }}\left(R T \ln \left(p / p_{0}\right)\right)}{-\sqrt{\frac{V_{\mathrm{tot}}}{V_{\mathrm{tot}}-V_{\mathrm{ads}}}} 2 \gamma(T) v_{\mathrm{l}}(T)}\right) \frac{\pi}{180}$.

For water in confinement at $25^{\circ} \mathrm{C}$, the values of $\gamma(T)$ and $v_{1}(T)$ are $71.69 \mathrm{mN} \mathrm{m}^{-1}$ and $20.5 \mathrm{~m}^{3} \mathrm{~mol}^{-1}$, respectively (Kocherbitov and Alfredsson, 2007). When deriving $\theta, p / p_{0}$ is identified as the saturation ratio where the pore condensation step of the DVS measurement is the steepest. 


\subsection{Ice nucleation measurements}

The mesoporous silica particles listed in Table 1 were tested in the Zurich Ice Nucleation Chamber (ZINC), a continuousflow diffusion chamber with a parallel plate geometry. The operating principal of ZINC can be found in Stetzer et al. (2008), and a brief description is given here. Aerosol particles are injected into ZINC, where they become sheathed between particle-free nitrogen in a region between two thermally controlled ice-coated walls. By applying a gradient in temperature between the two ice-coated walls, the temperature and supersaturation that the aerosols are exposed to is controlled. Depending on the aerosol properties and the set conditions in ZINC, aerosol particles may nucleate ice and continue to grow as they flow through the chamber until they reach an optical particle counter (OPC; Lighthouse Remote 3104) at the outlet of the chamber that counts and sizes the particles. All particles larger than $1 \mu \mathrm{m}$ are considered ice crystals and are thus counted as ice-nucleating particles at the set conditions in ZINC. To ensure that the particles counted by the OPC are truly ice crystals and not water droplets when conditions exceed water saturation, the particles pass through an isothermal section kept at ice saturation (water subsaturation) and the temperature equivalent to the warm wall prior to being sampled by the OPC, allowing any formed cloud droplets to evaporate while the ice crystals remain unchanged.

All RH scans between ice saturation and $105 \% \mathrm{RH}_{\mathrm{w}}$ were performed with a ramp rate of $2 \%$ increase in ice supersaturation per minute. At the start and end point of each scan, a 5 min background sample was taken by forcing the sample flow through a filter in order to determine the background noise of the chamber. The OPC counts from these background periods were averaged and then linearly interpolated to produce a background that was subtracted from each $\mathrm{RH}$ scan (Boose et al., 2016; Burkert-Kohn et al., 2017). An activated fraction $(\mathrm{AF})$ is calculated by comparing the number of particles larger than $1 \mu \mathrm{m}$ exiting ZINC as determined by the OPC $\left(N_{\text {ice(OPC) }}\right)$ and the number of aerosol particles entering the chamber $\left(N_{\text {aero(CPC) }}\right)$, as counted by a condensation particle counter (CPC; TSI 3787) upstream of ZINC given by

$\mathrm{AF}=\frac{N_{\text {ice }(\mathrm{OPC})}}{N_{\text {aero(CPC) }}}$.

\subsection{Aerosol generation}

The particles were aerosolized using a rotating brush generator (Palas, RGB-1000) supplied with evaporated liquid nitrogen (purity 6.0) to eliminate any residual humidity ( $\mathrm{RH}$ $<1 \%$ at $223 \mathrm{~K}$ ) and then passed through a $1 \mu \mathrm{m}$ cyclone (URG-2000-30EHB) to further lower the chance of large particles proceeding through the system before entering a $2.7 \mathrm{~m}^{3}$ stainless steel tank (Kanji et al., 2013). The tank was filled to a concentration between 4000 and $10000 \mathrm{~cm}^{-3}$, and a fan inside the tank ensured that the particles remained suspended. Before entering ZINC, the particles were size selected for $400 \mathrm{~nm}$ using a custom-built differential mobility analyzer (DMA), which consists of a polonium neutralizer and an electrostatic classifier (TSI 3082, long column). Even though the synthesis procedure in this study produces a narrow particle size distribution, the DMA was used to remove any particles larger than $1 \mu \mathrm{m}$ (from possible aggregation) to reduce the probability of misclassifying dry particles as ice crystals by the OPC.

\subsection{Differential scanning calorimetry}

In order to determine the ability of a critical ice embryo to fit into the pores of the samples tested, differential scanning calorimetry (DSC; TA Instruments Q10) was performed. The DSC technique detects phase changes based on the heat flow associated with them (e.g., Kumar et al., 2018; Marcolli et al., 2007). Bulk samples were prepared by mixing between 1 and $5 \mathrm{mg}$ of sample with ultrapure water (Sigma-Aldrich) or deionized water. Deionized water, which has a higher freezing temperature, was used for the large pore samples $(9.1 \mathrm{H} 2$ and $9.0 \mathrm{M} 2$ ) to achieve a separation between the bulk water and pore water freezing peaks. All DSC experiments were conducted with a cooling rate of $5 \mathrm{~K} \mathrm{~min}^{-1}$.

\section{Results}

The results are presented in three sections: the first characterizes the samples tested in this study (Sect. 3.1); the second investigates the ability of particles with $2.8 \mathrm{~nm}$ pores to nucleate ice depending on their water contact angle (Sect. 3.2); and the third investigates the role of pore diameter on ice nucleation as a function of surface functionalization (Sect. 3.3).

\subsection{Particle characterization}

\subsubsection{Particle surface area and pore diameter}

Nitrogen adsorption and NLDFT provide particle surface area $\left(S_{\mathrm{BET}}\right)$ and average pore diameter $\left(d_{\mathrm{DFT}}\right)$, respectively, and are summarized in Table 1 for each sample. The sample naming is such that the initial number represents the average pore diameter in nanometers followed by a $\mathrm{C}, \mathrm{M}$ or $\mathrm{H}$ to represent whether the sample was calcined, methylated or hydroxylated, respectively. The numbers 1 or 2 after the letter indicate whether the samples are independent synthesis batches or several batches that have been combined and then separated and functionalized in different ways, respectively. An overview of the pore size distributions of the samples is shown in Fig. 2. As evident from Fig. 2a, the methylation of the $2.8 \mathrm{~nm}$ sample led to a decrease in mean pore diameter by $0.1 \mathrm{~nm}(2.7 \mathrm{M} 2)$. The presence of trimethylsilyl groups is confirmed by our DRIFTS measurements (see Sect. 3.1.2), indicating that the methylation was successful. However, we 
cannot quantify the exact coverage and distribution of the trimethylsilyl groups. The addition of hydroxyl groups to the silica does not produce a difference in the pore size relative to the calcined sample (Fig. 2a). This suggests that the $\mathrm{OH}$ groups do not detectably reduce the pore width or that the pore surface of the calcined sample is already sufficiently hydroxylated, as discussed below.

The pore size distributions of the hydroxylated samples are shown in Fig. 2b. The $2.8 \mathrm{~nm}$ samples, $2.8 \mathrm{H} 1$ and $2.8 \mathrm{H} 2$, are quite similar; however $2.8 \mathrm{H} 1$ has a larger fraction of $2.6 \mathrm{~nm}$ pores. $2.5 \mathrm{H} 1$ has the narrowest pore size distribution and the lowest total pore volume of the hydroxylated samples as shown in Table 1. Meanwhile, $3.3 \mathrm{H} 1$ has the broadest pore size distribution with pores ranging from 2.7 to $4.5 \mathrm{~nm}$. The methylated samples show a similar trend with a broadening of pore size distribution with increasing average pore diameter (see Fig. 2c). Consistent with functionalization, the methylated samples have lower pore volumes than the corresponding hydroxylated samples (see $V_{\text {Ptot }}$ in Table 1). This provides additional evidence that the methylation procedure was effective. The SBA samples $(9.1 \mathrm{H} 2$ and $9.0 \mathrm{M} 2)$ show a similar trend with a slight decrease in pore diameter upon methylation (Fig. 2d). As shown in Table 1, there is no relationship between the total BET surface area and pore diameter except when comparing the MCM-41 to the SBA-15 samples which have approximately half of the specific surface area due to their differing morphology and pore structure.

\subsubsection{DRIFTS}

When comparing the impact of functionalization on the same initial bulk sample (2.8C2), the difference between hydroxylation $(2.8 \mathrm{H} 2)$ and methylation $(2.7 \mathrm{M} 2)$ is visible in the DRIFTS spectra (Fig. 3a). The intensity in the O-H stretching region, $3200-3800 \mathrm{~cm}^{-1}$ is much larger for the hydroxylated sample $(2.8 \mathrm{H} 2)$ than the calcined $(2.8 \mathrm{C} 2)$ and methylated (2.7M2) samples, consistent with the addition of hydroxyl groups during the hydroxylation process. The broad absorption band peaking at about $3450 \mathrm{~cm}^{-1}$ (3000$3700 \mathrm{~cm}^{-1}$ ) in the calcined, hydroxylated and methylated samples is indicative of water adsorbed on the silica surface and residual silanol groups (Chen et al., 1996). Previous studies have shown that calcining silica particles at temperatures above $200^{\circ} \mathrm{C}$, as is the case for our calcined samples, removes all free water (Muster et al., 2001; Zhuravlev, 2000). However, here the DRIFTS cell was operated at ambient conditions, allowing for water to (re-)adsorb to the particle surface and contributing to the broad absorption in the range $3000-3700 \mathrm{~cm}^{-1}$ (Muster et al., 2001). Indeed, when exposing a silica sample calcined at $200^{\circ} \mathrm{C}$ to ambient conditions, the increase in mass due to adsorbed water is visible using thermogravimetric analysis (not shown). The methylated sample $(2.7 \mathrm{M} 2)$ has the weakest absorbance in the $\mathrm{OH}$ stretching region $\left(3000-3700 \mathrm{~cm}^{-1}\right.$; see Fig. 3a).
Furthermore, the methylated sample shows a peak associated with the C-H stretching band around $2960 \mathrm{~cm}^{-1}$, indicating the presence of trimethylsilyl groups bonded to the silica surface. However, the presence of isolated and geminal silanol groups, as shown by the peak at $3750 \mathrm{~cm}^{-1}$, indicates that the methylation is incomplete (Bergna, 1994; Muster et al., 2001). The increase in the $\mathrm{C}-\mathrm{H}$ stretching band due to the methylation (at $2960 \mathrm{~cm}^{-1}$ ), roughly corresponds to the decrease in the isolated silanol/geminal silanol peak for the $2.8 \mathrm{~nm}$ samples (Fig. 3a). The calcined sample (2.8C2) has the highest concentration of isolated and geminal silanol groups. This is expected as during hydroxylation $(2.8 \mathrm{C} 2$ transitioning to $2.8 \mathrm{H} 2$ ) the concentration of silanol groups increases and becomes sufficiently dense for chains of hydrogen bonds to form between individual silanol groups, decreasing the number of isolated silanol groups and thereby shifting the peak at 3750 to $\sim 3660 \mathrm{~cm}^{-1}$ (Muster et al., 2001).

When comparing the DRIFTS results of the different hydroxylated and methylated samples (Fig. $3 b$ and c), it is clear that the SBA-15 particles $(9.1 \mathrm{H} 2$ and $9.0 \mathrm{M} 2)$ also show absorbance in the $\mathrm{OH}\left(3200-3800 \mathrm{~cm}^{-1}\right)$ and $\mathrm{CH}(\sim$ $2960 \mathrm{~cm}^{-1}$ ) stretching region of the spectra, respectively, demonstrating that the functionalization was successful. Differing peak intensities between particle types could be due to the differing densities of silanol and siloxanes on the surface of the particles. Although the clear peak in the $\mathrm{C}-\mathrm{H}$ stretch region of the DRIFTS (Fig. 3c) shows that the methylation process on the SBA-15 particles $(9.1 \mathrm{H} 2$ functionalization to 9.0M2) was successful, methylation is far from complete since the peak arising from isolated/geminal silanol stretching vibrations $\left(3750 \mathrm{~cm}^{-1}\right)$ is still visible in all methylated samples (Fig. 3c). The concentration of hydroxyl groups on the hydroxylated samples is independent of pore size (Fig. 3). Rather, the intensity in the $\mathrm{O}-\mathrm{H}$ stretching region likely depends on the age and exposure of the calcined samples to ambient water vapor. The methylated samples show much less spread in the amount of adsorbed water, suggesting that they are more resistant to hydroxylation and more stable over time (Fig. 3c).

\subsubsection{Water vapor sorption}

Two water vapor sorption cycles were obtained for the samples $2.4 \mathrm{M} 1,2.5 \mathrm{H} 1,3.3 \mathrm{M} 1,3.3 \mathrm{H} 1,9.1 \mathrm{H} 2$ and $9.0 \mathrm{M} 2$, and the resultant isotherms are shown in Fig. 4. The sorption isotherms have been classified following the recommendation by the International Union of Pure and Applied Chemistry (IUPAC; Sing, 2009; Thommes et al., 2015). The hydroxylated samples $(2.5 \mathrm{H} 1,3.3 \mathrm{H} 1$ and $9.1 \mathrm{H} 2)$ show Type IV isotherms, characterized by an initial monolayer-multilayer adsorption occurring on the pore wall followed by a steep, almost step-like increase in water mass known as the condensation step at the $p / p_{0}$ or RH associated with pore filling. This is consistent with previous observations for mesoporous 

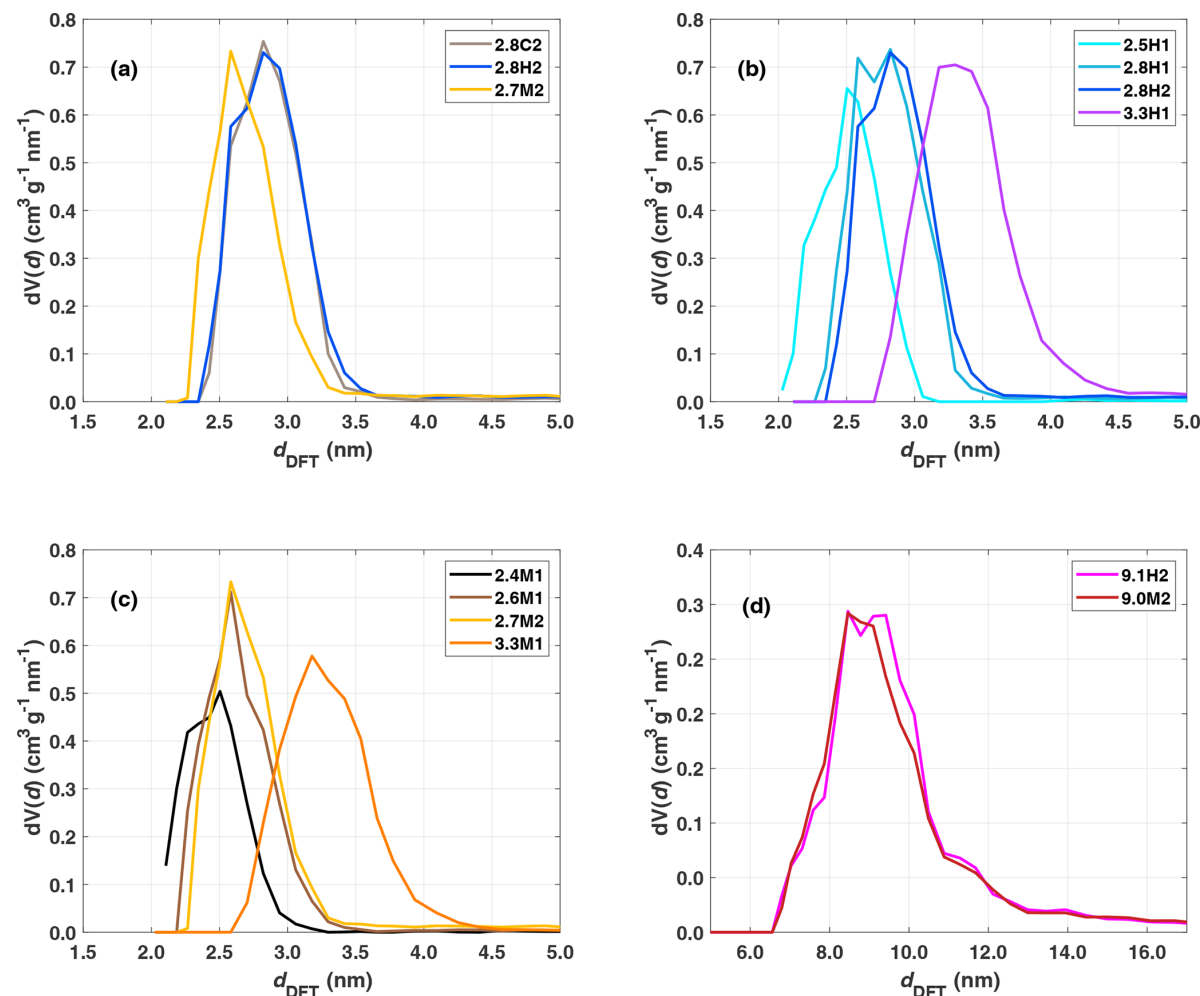

Figure 2. Panel (a) shows pore size distributions for the $2.8 \mathrm{~nm}$ sample after calcination (grey), hydroxylation (blue) and methylation (gold). Panels (b) and (c) show pore size distributions of the hydroxylated and methylated samples, respectively. Panel (d) shows the pore size distribution for the SBA-15 samples after hydroxylation (magenta) and methylation (red).

Table 1. Summary of samples used for ice nucleation studies. The BET method was used for total surface area $\left(S_{\mathrm{BET}}\right)$ and $\alpha_{\mathrm{S}}$ plot for external surface area $\left(S_{\mathrm{EXT}}\right)$ (Bhambhani et al., 1972). The total pore volume $\left(V_{\mathrm{Ptot}}\right)$ was taken at $p / p_{0}=0.95$.

\begin{tabular}{llllrlrl}
\hline $\begin{array}{l}\text { Sample } \\
\text { name }\end{array}$ & $\begin{array}{l}\text { Synthesis } \\
\text { method }\end{array}$ & $d_{\text {DFT }}$ & Functionalization & $\begin{array}{r}S_{\mathrm{BET}} \\
\left(\mathrm{m}^{2} \mathrm{~g}^{-1}\right)\end{array}$ & $\begin{array}{l}S_{\text {EXT }} \\
\left(\mathrm{m}^{2} \mathrm{~g}^{-1}\right)\end{array}$ & $\begin{array}{r}V_{\text {Ptot }} \\
\left(\mathrm{cm}^{3} \mathrm{~g}^{-1}\right)\end{array}$ & $\begin{array}{l}\theta \\
\left({ }^{\circ}\right)\end{array}$ \\
\hline $3.3 \mathrm{M} 1$ & MCM-41 & $3.3 \mathrm{~nm}( \pm 0.3)$ & Methyl & 726 & 12 & 0.50 & $75-80$ \\
$3.3 \mathrm{H} 1$ & MCM-41 & $3.3 \mathrm{~nm}( \pm 0.3)$ & Hydroxyl & 893 & 22 & 0.66 & $41-45$ \\
$2.4 \mathrm{M} 1$ & MCM-41 & $2.4 \mathrm{~nm}( \pm 0.2)$ & Methyl & 822 & 7 & 0.33 & $75-80$ \\
$2.5 \mathrm{H} 1$ & MCM-41 & $2.5 \mathrm{~nm}( \pm 0.2)$ & Hydroxyl & 892 & 7 & 0.38 & $41-45$ \\
$2.6 \mathrm{M} 1$ & MCM-41 & $2.6 \mathrm{~nm}( \pm 0.2)$ & Methyl & 917 & 12 & 0.42 & NA \\
$2.8 \mathrm{H} 1$ & MCM-41 & $2.8 \mathrm{~nm}( \pm 0.2)$ & Hydroxyl & 1007 & 15 & 0.53 & NA \\
$2.7 \mathrm{M} 2$ & MCM-41 & $2.7 \mathrm{~nm}( \pm 0.2)$ & Methyl & 925 & 13 & 0.45 & NA \\
$2.8 \mathrm{C} 2$ & MCM-41 & $2.8 \mathrm{~nm}( \pm 0.2)$ & Calcined & 868 & 12 & 0.49 & NA \\
$2.8 \mathrm{H} 2$ & MCM-41 & $2.8 \mathrm{~nm}( \pm 0.2)$ & Hydroxyl & 920 & 14 & 0.53 & NA \\
$9.0 \mathrm{M} 2$ & SBA-15 & $9.0 \mathrm{~nm}( \pm 1.1)$ & Methyl & 399 & NA & 0.95 & $60-71$ \\
$9.1 \mathrm{H} 2$ & SBA-15 & $9.1 \mathrm{~nm}( \pm 1.1)$ & Hydroxyl & 429 & NA & 0.98 & $15-37$ \\
\hline
\end{tabular}

NA - not available

silica (Kittaka et al., 2011). The methylated samples, 2.4M1, 3.3M1 and 9.0M2 show similar isotherms but lack an initial monolayer adsorption along the uptake curves. This is consistent with a Type $\mathrm{V}$ isotherm and provides direct evidence that the methylation was successful in making the particles more hydrophobic. It should be highlighted that in the second sorption cycle, the methylated samples have Type IV isotherms that are more similar to the isotherms of the hydroxylated samples, independent of the pore size. This transition suggests that the exposure to high concentrations of water vapor during the first sorption cycle increases the number of silanol groups on the surface of the methylated samples. Indeed, the second sorption cycle of the methylated samples shows that the condensation step shifts close to the $\mathrm{RH}$ of the 

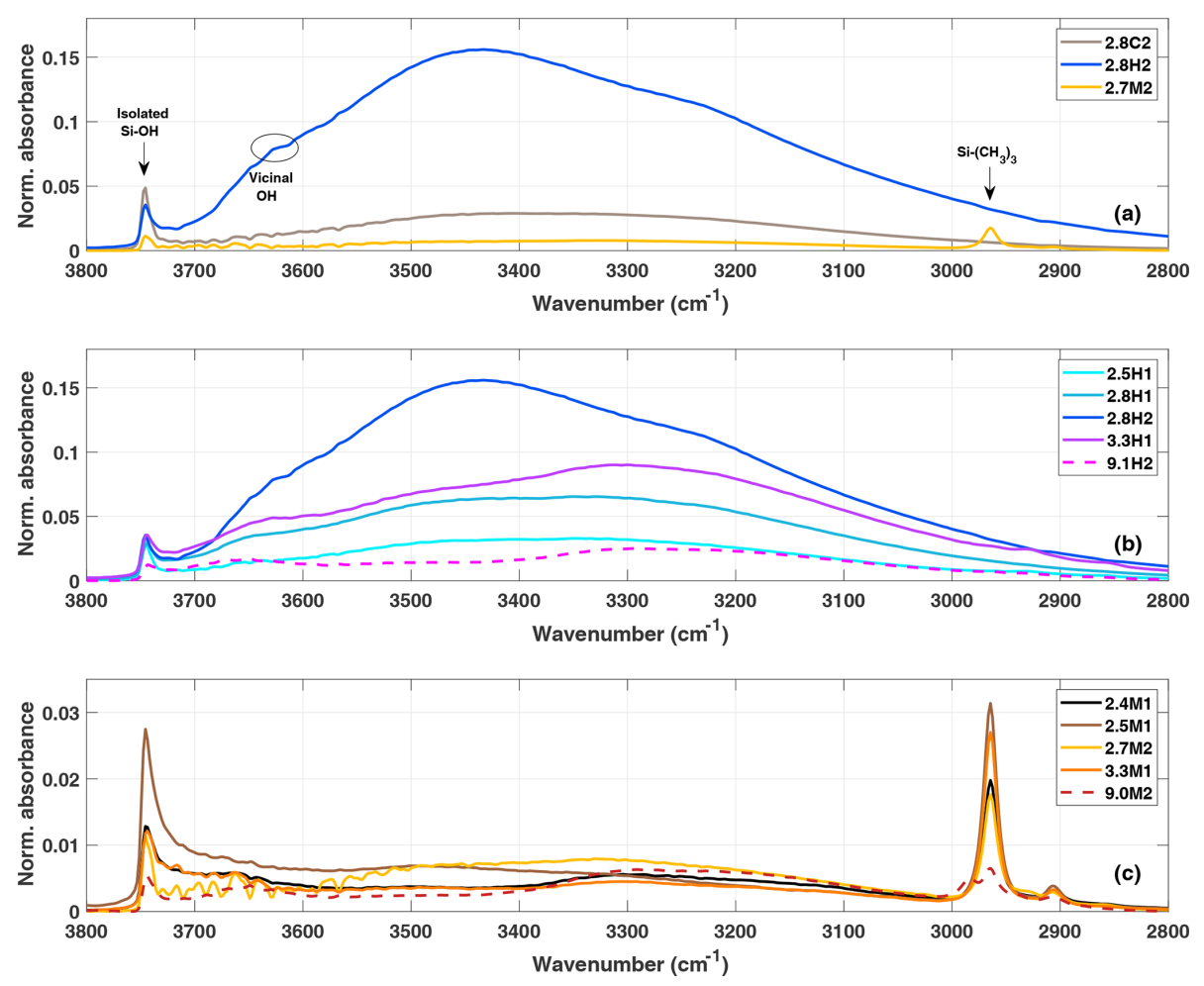

Figure 3. (a) DRIFTS normalized absorbance (Kubelka-Munk) for the $2.8 \mathrm{~nm}$ particles after calcination (grey), hydroxylation (blue) and methylation (gold). Panels (b) and (c) show the spectra of hydroxylated and methylated samples, respectively.

hydroxylated sample during the first sorption cycle. This indicates that the water contact angle of the methylated sample becomes closer to that of the hydroxylated sample.

Similarly, the shift in the condensation step to lower humidities for the hydroxylated samples suggests a decrease in water contact angle. The relative mass of the hydroxylated samples does not return to zero after the desorption cycle (Fig. 4a and b), indicating that water remains adsorbed on the particles. This strongly adsorbed water is expected to lower the water contact angle between water and the wall surface to nearly zero. Moreover, multilayers of adsorbed water narrow the effective diameter for pore filling (Broekhoff and de Boer, 1967; Kruk et al., 1997; Miyahara et al., 2000). Both effects explain the observed shift of the condensation step to lower humidities. Furthermore, it is visible from Fig. 4 that the hydroxylated samples adsorb relatively more water than the methylated samples even though they have very similar pore diameters (see $d_{\mathrm{DFT}}$ in Table 1 ). However, the samples have differing total pore volumes $\left(V_{\text {Ptot }}\right)$, and thus, it is expected that the absolute amount of condensed water differs.

The water contact angle of the samples is obtained by inserting the RH of the condensation step in the first water sorption cycle into Eq. (7) (see Table 1). The water contact angles for the MCM-41 particles ranged between $41-45^{\circ}$ and $75-80^{\circ}$, for the hydroxylated and methylated samples, respectively, based on the observed value and uncertainty in the measured $d_{\mathrm{DFT}}$. Conversely, the SBA-15-type samples have significantly lower water contact angles of 15 and $60^{\circ}$ for the hydroxylated $(9.1 \mathrm{H} 2)$ and methylated $(9.0 \mathrm{M} 2)$ samples, respectively. However, these values may be due to the large spread in the pore diameters within the sample. As can be seen from Fig. 2, the pore size distribution is significantly wider for the SBA-15 samples than for the MCM-41 particles (ranges from $\sim 7$ to $16 \mathrm{~nm}$ with a clear maximum in the size distribution at $9 \mathrm{~nm}$ ). Therefore, it is difficult to properly assign the correct pore diameter responsible for the initial pore condensation observed from the sorption measurements based on the uncertainty in $d_{\mathrm{DFT}}$ alone $( \pm 1.1 \mathrm{~nm})$. If $7 \mathrm{~nm}$ is used as the pore diameter instead of 9.1 or $9.0 \mathrm{~nm}$ and the RH of the initial uptake in pore water from the sorption measurements is used, the water contact angles for $9.1 \mathrm{H} 2$ and $9.0 \mathrm{M} 2$ become 37 and $71^{\circ}$, respectively.

\subsubsection{DSC measurements}

Upon cooling of a sample prepared as a slurry in the DSC, the exterior water freezes first followed by the freezing of pore water due to the decrease in temperature required for water in confinement to freeze (Deschamps et al., 2010; Janssen et al., 2004; Jelassi et al., 2010; Kittaka et al., 2011; Marcolli, 2014; Moore et al., 2012; Morishige and Uematsu, 2005). This can most clearly be seen in the freezing of 3.3M1 shown in Fig. 5a where the initial release of latent heat (peak) cen- 

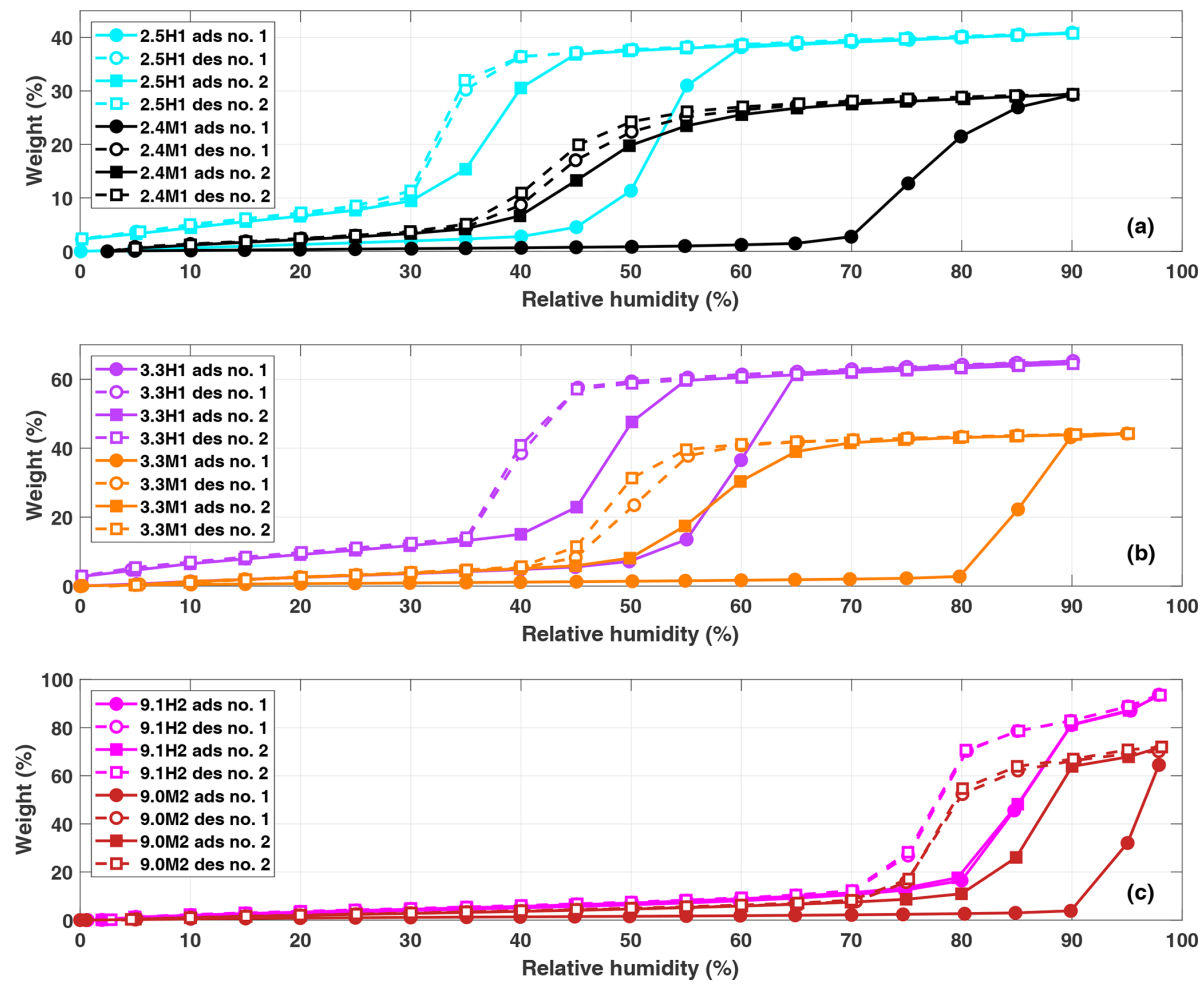

Figure 4. Water sorption isotherms for 2.5H1 (cyan) and 2.4M1 (black) in (a), 3.3H1 (purple or lilac) and 3.3M1 (orange) in (b), and 9.1H2 (magenta) and 9.0M2 (dark red) in (c). The solid and dashed lines with closed and open symbols indicate adsorption and desorption isotherms, respectively. The first and second adsorption/desorption cycles are indicated by circles and squares, respectively.

tered around $255 \mathrm{~K}$ is due to the freezing of the exterior bulk water followed by the second peak starting at $234 \mathrm{~K}$ due to the freezing of the pore water. Tap water was used for the experiments with the SBA-15 samples to shift the freezing of exterior water to higher temperatures so that the freezing of pore water is observable (Fig. 4c). Also shown in Fig. 5 are the expected critical pore diameters $D_{\mathrm{p}}$ calculated following Eqs. (2) and (3), yielding a direct comparison of the theoretical predictions of pore freezing to the experimentally determined onset of ice formation (peaks in thermograms). Since previous MDS and X-ray diffraction studies have shown ice in confinement to be typically stacking disordered or cubic (Moore et al., 2010, 2012; Morishige et al., 2009) two parameterizations from literature (Murray et al., 2010; Zobrist et al., 2007) were used to calculate $D_{\mathrm{p}}$, assuming either cubic (Fig. 5a and b) or hexagonal ice (Fig. 5c). As can be seen in Fig. 5, the parameterization assuming cubic ice is more accurate at predicting the observed freezing temperature for narrow mesopores ( 2.8 and $3.3 \mathrm{~nm}$ samples) where the freezing temperatures are around $230 \mathrm{~K}$. In contrast, the freezing temperature of the $9.1 \mathrm{~nm}$ pore samples $(9.1 \mathrm{H} 2$ and $9.0 \mathrm{M} 2$; Fig. 4c) of approximately $261 \mathrm{~K}$ is better predicted assuming that the ice is hexagonal. These results are consistent with studies that have shown that cubic ice occurs more readily at colder temperatures (Kuhs et al., 2012; Malkin et al., 2015).
The DSC thermograms of the SBA- 15 samples $(9.1 \mathrm{H} 2$ and 9.0M2) show a bimodal peak associated with the freezing of pore water (see Fig. 5c), with a pronounced peak around $258 \mathrm{~K}$ and a shoulder towards higher $T$. This indicates that there is a bimodal distribution of pore sizes that contribute differing fractions of pore volume to the samples. Indeed, the pore size distributions show that the SBA-15 samples have a clear shoulder in the distribution at $11 \mathrm{~nm}$ followed by a main peak at $9.1 \mathrm{~nm}$ (see Fig. 2d). Thus the bimodal freezing signal is likely due to the freezing of pore water in pores larger than $11.0 \mathrm{~nm}$ followed by the release of heat from the freezing in the smaller, more abundant $9.1 \mathrm{~nm}$, remaining pores.

Deschamps et al. (2010) showed that highly hydrophobic pore surfaces had lower melting and freezing temperatures than hydrophilic pores of the same diameter. They associated the depressed freezing temperatures with a decrease in mobility of water molecules in hydrophobic mesopores. However, as the pore size exceeded $3 \mathrm{~nm}$, the dependence on pore hydrophobicity of the freezing point depression disappeared (Deschamps et al., 2010; Jähnert et al., 2008; Schreiber et al., 2001). In agreement with a loss of the dependence on hydrophobicity for pores larger than $3 \mathrm{~nm}$, Moore et al. (2012) showed that the melting temperature in a $4 \mathrm{~nm}$ diameter silica pore was the same regardless of hydrophobicity using MDS. The DSC thermographs in Fig. 5 show that there is no detectable difference in the onset freezing temperatures for the 
SBA-15 samples depending on functionalization $(9.1 \mathrm{H} 2$ and 9.0M2; Fig. 5c). However, in contrast to the results of Deschamps et al. (2010), the $2.8 \mathrm{~nm}$ (Fig. 5b) samples also show no detectable difference in freezing onset. This indifference may stem from the fact that the observed freezing onsets occur due to the ice growth in the largest detectable pores of a sample. As can be seen from Fig. 2, both $2.8 \mathrm{H} 2$ and $2.7 \mathrm{M} 2$ contain a fraction of pores larger than $3 \mathrm{~nm}$. Therefore, the observed freezing onsets in the thermograms may be due to pore diameters that are wide enough for growing ice to not be impacted by the water contact angle of the pore wall (Moore et al., 2012).

\subsection{Pore condensation and freezing experiments: the $2.8 \mathrm{~nm}$ pore example}

A summary of the ice formation activity of the functionalized $2.8 \mathrm{~nm}$ particles from a single batch $(2.8 \mathrm{H} 2,2.8 \mathrm{C} 2$ and 2.7M2) is shown in Fig. 6, where the $\mathrm{RH}_{\mathrm{i}}$ values required for an $\mathrm{AF}$ of $0.05\left(\mathrm{AF}_{0.05}\right)$ are shown. An $\mathrm{AF}$ of 0.05 was chosen as best representing the average freezing $\mathrm{RH}$ of the porous particles. The complete AF curves are shown in Appendix A1. The onset $\mathrm{RH}_{\mathrm{i}}$ at 223 and $228 \mathrm{~K}$ is significantly lower for the hydroxylated (blue) and calcined (grey) samples than for the methylated sample (gold). This reveals a strong dependence on the water contact angle, which is lower in case of the hydroxylated sample $\left(\theta=41-45^{\circ}\right)$ compared to the methylated sample $\left(\theta=75-80^{\circ}\right)$. The lower onset humidity of the hydroxylated sample is consistent with the inverse Kelvin effect, which predicts pore filling to occur at a lower $\mathrm{RH}_{\mathrm{i}}$ for the hydroxylated sample. Furthermore, the pore filling line based on Eq. (1) for the methylated sample (assuming $\theta=78^{\circ}$ ) predicts the observed freezing onsets at 223 and $228 \mathrm{~K}$ (gold line, $\mathrm{AF}_{0.05}$ ), respectively, within experimental uncertainty, indicating that the PCF mechanism is limited by pore filling. Additionally, this suggests that the ice formed in the methylated pores investigated here is capable of growing into the unconfined vapor region as proposed by David et al. (2019) without the need for a two-step nucleation process (Christenson, 2013; Kovács and Christenson, 2012; Page and Sear, 2006). In contrast, the $2.8 \mathrm{~nm}$ hydroxylated sample $(2.8 \mathrm{H} 2)$ is predicted to fill below ice saturation $\left(\mathrm{RH}_{\mathrm{i}} \geq 71 \%\right.$ at $223 \mathrm{~K}$ and $\mathrm{RH}_{\mathrm{i}} \geq 69 \%$ at $\left.228 \mathrm{~K}\right)$. Therefore, ice growth should be observed as soon as ice saturation is exceeded within $\mathrm{ZINC}$, yet a $\mathrm{RH}_{\mathrm{i}}$ of $118 \%(223 \mathrm{~K})$ and $112 \%$ $\left(228 \mathrm{~K}\right.$ ) is required to observe an $\mathrm{AF}_{0.05}$ (Fig. 6). This might suggest that a two-step nucleation mechanism is required for ice to grow out of narrow calcined and hydroxylated mesopores at these lower supersaturations (Campbell et al., 2017; Christenson, 2013). However, particles must grow to at least $1 \mu \mathrm{m}$ before they are detected as ice crystals in this study (see Sect. 2.3). Hence, the limited growth time in ZINC $(\sim 10 \mathrm{~s})$ for the particles to reach a size of $1 \mu \mathrm{m}$ must be accounted for when interpreting ice onset. Therefore, we calculated theoretical ice growth curves (dashed salmon lines - see Ap- pendix A2 for calculation) using the parameterization from Rogers and Yau (1989) and assuming accommodation coefficients of 0.1 and 0.2 for ice growth at $T<$ HFT (Earle et al., 2010; Isono and Iwai, 1969; Magee et al., 2006; Skrotzki et al., 2013). The ice crystal shape in the growth calculation was assumed to be spherical due to the small final size $(\sim 1 \mu \mathrm{m})$ and its growth on spherical particles (Harrington et al., 2019). Comparing our ice onsets to the expected growth (dashed salmon lines, Fig. 6), the slow ice crystal growth may explain the required $\mathrm{RH}_{\mathrm{i}}$ to observe ice within the ZINC experiments, without the need of a two-step nucleation mechanism (David et al., 2019). Moreover, the reported AF values of 0.05 do not correspond to the ice onset. Considering Fig. A1, the initial ice observed is at $\mathrm{RH}_{\mathrm{i}}$ values of $110 \%$ and $108 \%$ for 223 and $228 \mathrm{~K}$, respectively. Lupi et al. (2017) and Moore et al. (2010) have shown in MDS that stacking disordered ice is formed in confinement and during nucleation, requiring a humidity higher than $100 \%$ to grow ice. Additionally, the calculated humidity that particles are exposed to in ZINC depends on the temperatures of the warm and cold walls, which are measured by thermocouples that have an uncertainty of $\pm 0.1 \mathrm{~K}$ (Stetzer et al., 2008). This uncertainty $( \pm 5 \%)$ can lead to a higher reported humidity than required to observe ice nucleation and is included in the vertical error bars in Figs. 6, 7 and 8.

In a PCF mechanism, it is expected that once the critical humidity for pore filling is reached, ice nucleation and growth should lead to a step-like increase in AF to values close to unity. Yet the increase in $\mathrm{RH}_{\mathrm{i}}$ between onset and $\mathrm{AF}_{0.05}$ (Figs. $\mathrm{A} 1$ and $\mathrm{A} 2$ ) indicates that either the pores on the particles are not homogeneous in both pore size and/or water contact angle or the conditions within ZINC are nonuniform. Indeed, Garimella et al. (2017) showed that turbulence at the entrance of the chamber causes particles to leave the (predicted) aerosol lamina, and therefore, these particles experience a lower $\mathrm{RH}_{\mathrm{i}}$ than the ones in the lamina. The assumption that all particles are within the lamina leads therefore to a low bias of $\mathrm{AF}$ at all $\mathrm{RH}_{\mathrm{i}}$ and a shift of $\mathrm{AF}=1$ to higher $\mathrm{RH}_{\mathrm{i}}$. The underestimation of the $\mathrm{AF}$ depends on the set temperature and ice supersaturation (gradient between the wall temperatures). At $233 \mathrm{~K}$ and $102 \% \mathrm{RH}_{\mathrm{w}}$, only $78 \%$ of the particles were shown to be exposed to the set conditions in ZINC (Garimella et al., 2017). Particles deviating from the lamina likely explain the gradual increase in the AF with increasing $\mathrm{RH}_{\mathrm{i}}$.

The shift of the $\mathrm{AF}_{0.05}$ close to water saturation at $233 \mathrm{~K}$ (Fig. 6) is consistent with the DSC measurements, which show that the pore water only starts to freeze at $230 \mathrm{~K}$ for $2.7-2.8 \mathrm{~nm}$ pore diameter samples (Fig. $5 \mathrm{~b}$ ), suggesting that the pores are too narrow for PCF to occur at $233 \mathrm{~K}$. Rather, bulk water on the particle surface is required for homogeneous freezing consistent with the observed shift of the $\mathrm{AF}_{0.05}$ to water saturation at $233 \mathrm{~K}$.

When examining the entirety of AF curves at $233 \mathrm{~K}$ shown in Figs. A1c and A2c, there is a clear increase in AF to ap- 

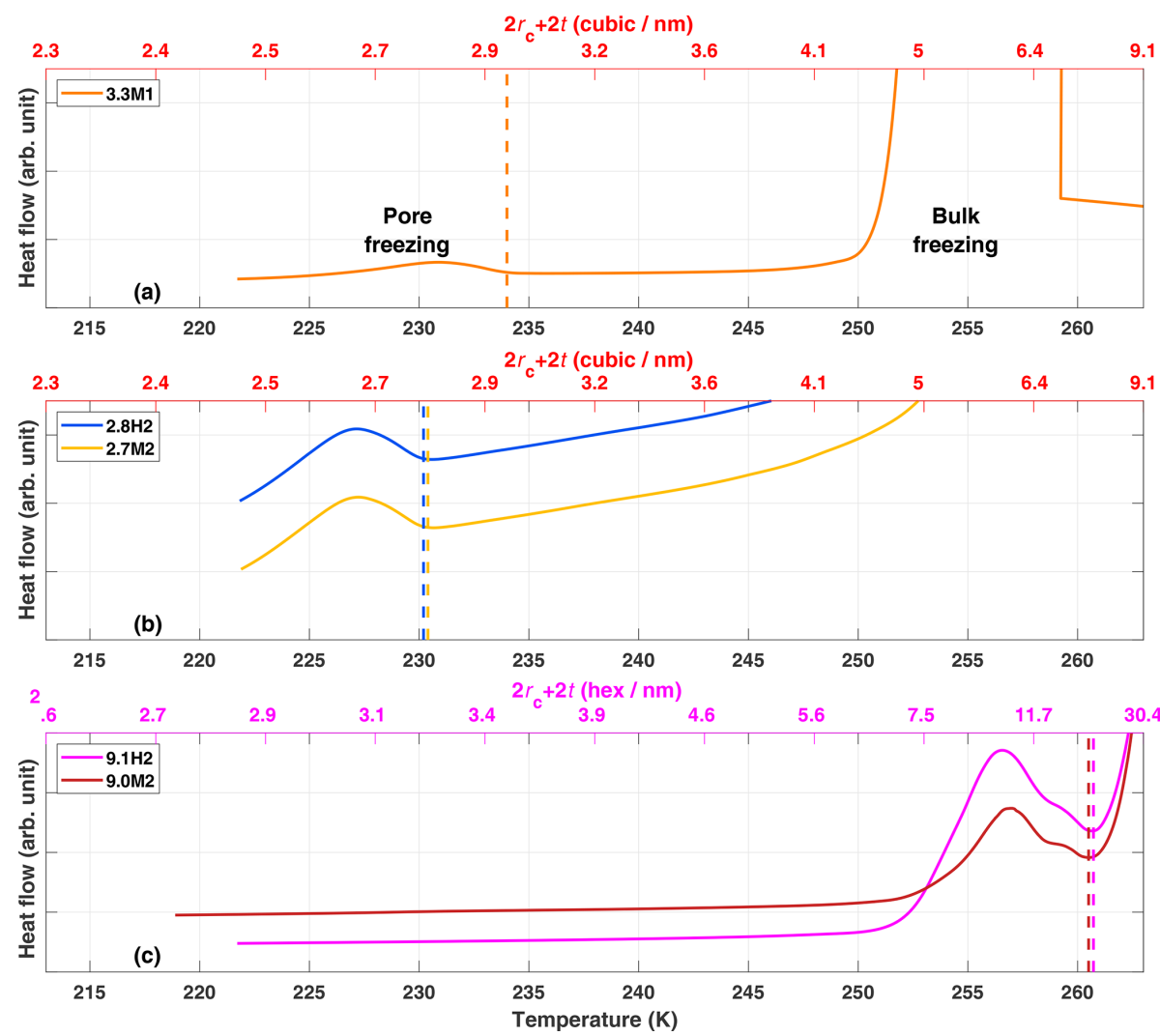

Figure 5. DSC thermograms for ice growth into pores for samples (a) 3.3M1, (b) $2.8 \mathrm{H} 2$ and 2.7M2, and (c) $9.1 \mathrm{H} 2$ and $9.0 \mathrm{M} 2$. The vertical dashed lines mark the observed onset temperatures of pore freezing. The upper $x$ axes represent the predicted critical pore diameter $\left(2 r_{\mathrm{c}}+2 t\right)$ for cubic (red axis labels; $\mathbf{a}$ and b) or hexagonal (magenta axis labels; $\mathbf{c}$ ) ice to be stable, following Marcolli (2014). The peak on the righthand side of panel (a) and the descending lines in panel (c) are due to the bulk freezing of exterior water.

proximately 0.02 for the hydroxylated sample $(2.8 \mathrm{H} 2)$ between $100 \%$ and $120 \% \mathrm{RH}_{\mathrm{i}}$ and a slight increase of 0.002 for the methylated sample (2.7M2). This suggests that a fraction of the pores small enough to remain undetected in the DSC (see Sect. 3.1.4) nucleate ice homogeneously at $233 \mathrm{~K}$ because they exhibit diameters $>3 \mathrm{~nm}$, which is large enough to accommodate the critical ice germs. Such an assumption is in agreement with the tail of pores with $d_{\text {DFT }}>3 \mathrm{~nm}$ appearing in the pore size distribution of the samples in Fig. 2a. Following Marcolli (2014) for calculating $D_{\mathrm{p}}$ (see Eq. 3), cubic or stacking disordered ice should be stable in pores of approximately $3 \mathrm{~nm}$ diameter at $233 \mathrm{~K}$ (see Fig. 5b; Moore et al., 2010; Morishige et al., 2009). However, even if the pore diameter is large enough to host a critical ice germ, ice may fail to form during the residence time in ZINC when the nucleation rate within the pore water is too low. Using rates for homogenous ice nucleation derived from experiments, $J_{\text {hom }}(T)$ (Atkinson et al., 2016; Ickes et al., 2015; Riechers et al., 2013), the residence time in ZINC ( $t_{\text {ZINC }}$ ) for a given pore volume ( $\left.V_{\text {pore }}\right)$ to nucleate ice can be calculated as

$t_{\mathrm{ZINC}}=\frac{-\ln (1-\mathrm{AF})}{J_{\mathrm{hom}}(T) V_{\mathrm{pore}}}$.
Using $J_{\text {hom }}(T)$ of $10^{10-12} \mathrm{~cm}^{-3} \mathrm{~s}^{-1}$ at $233 \mathrm{~K}$ as reported in literature (Ickes et al., 2015; Koop and Murray, 2016; Murray et al., 2010) and $V_{\text {pore }}$ based on a single pore with average width and the length of an average particle $(400 \mathrm{~nm})$, the residence time in ZINC would need to be 3 to 4 orders of magnitude longer than the $\sim 10 \mathrm{~s}$ available in order to reach an $\mathrm{AF}_{0.05}$. Therefore, the observed increase in the AF to 0.02 for $2.8 \mathrm{H} 2$ (Fig. A1c) does not comply with reported homogeneous ice nucleation rates but may be explained by the effect of pressure. As RH decreases, tension (negative pressure) builds up in the pore water as a function of the curvature of the water meniscus at the pore opening, such that nucleation rates increase drastically (Marcolli, $2020)$. At the $\mathrm{RH}$ of pore filling $\left(\mathrm{RH}_{\mathrm{w}}=67 \%\right)$, the pore water experiences a strongly negative pressure $(-83 \mathrm{MPa})$. At $233 \mathrm{~K}$ and water saturation $(P=0.1 \mathrm{MPa})$, the pressuredependent extension of the Murray et al. (2010) parameterization of CNT (Marcolli, 2020) predicts a nucleation rate of $9 \times 10^{10} \mathrm{~cm}^{-3} \mathrm{~s}^{-1}$ (when using an exponent of $n=0.97$ for estimating $\sigma_{\text {iw }}$ following Murray et al., 2010). However, at $\mathrm{RH}_{\mathrm{w}}=67 \%(P=-83 \mathrm{MPa})$ the nucleation rate increases to over $10^{21} \mathrm{~cm}^{-3} \mathrm{~s}^{-1}\left(4 \times 10^{22} \mathrm{~cm}^{-3} \mathrm{~s}^{-1}\right)$, which should result in freezing of pore water in less than a millisecond. Note that 


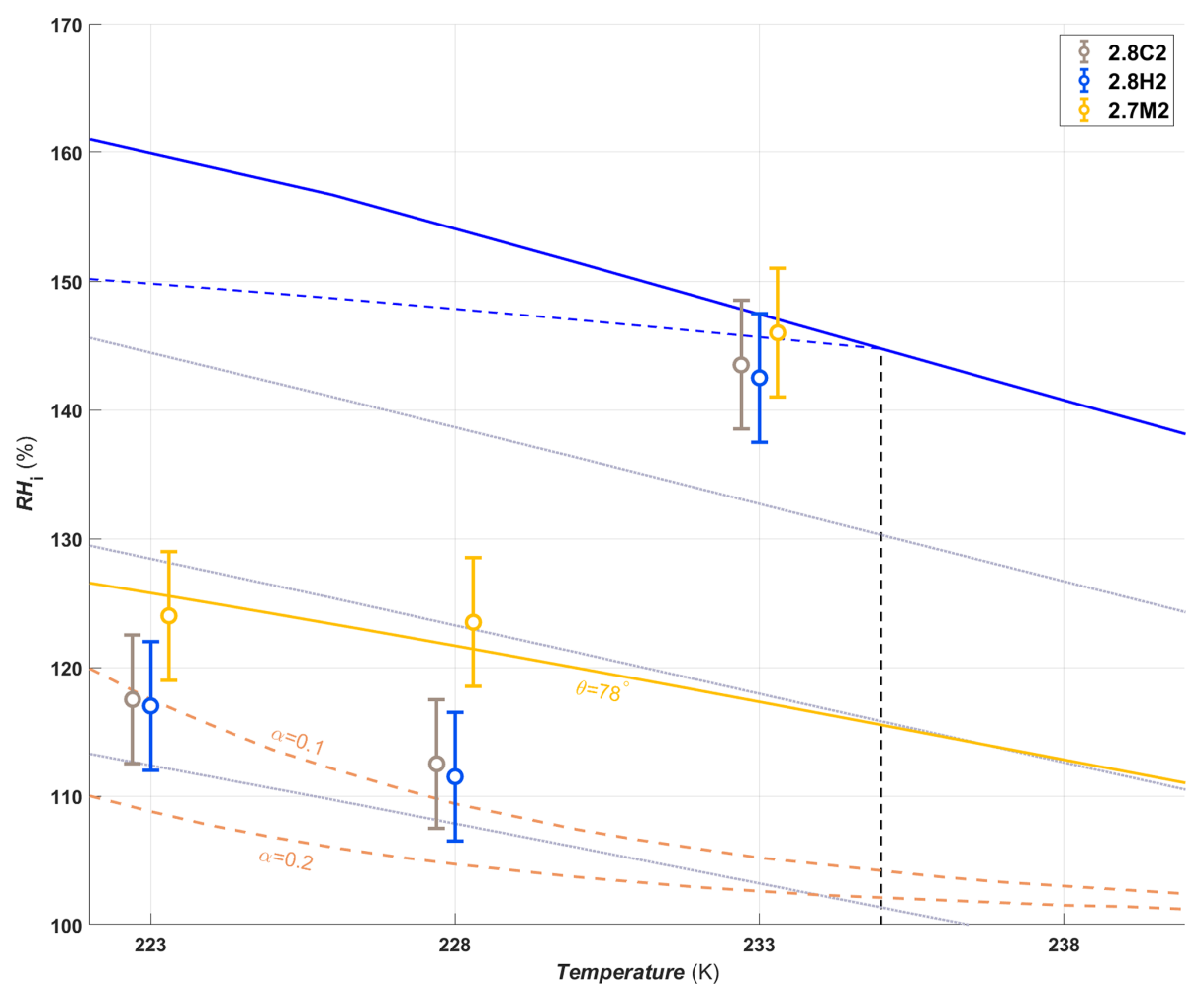

Figure 6. The average $\mathrm{RH}_{\mathrm{i}}$ required for an $\mathrm{AF}_{0.05}$ for the hydroxylated (blue), methylated (gold) and calcined (grey) porous (2.7-2.8 nm) silica samples. The error bars represent the maximum uncertainty in the calculated $\mathrm{RH}_{\mathrm{i}}( \pm 5 \%)$ in $\mathrm{ZINC}$ arising from the uncertainty in the reported thermocouple temperature $( \pm 0.1 \mathrm{~K}$; Stetzer et al., 2008) and encompass the standard deviation from averaging the experiments. The solid blue line and dotted grey lines represent water saturation and constant $\mathrm{RH}_{\mathrm{W}}$ decreasing in steps of $10 \%$ from the water saturation line, respectively. The dashed blue line is the homogeneous nucleation $\mathrm{RH}_{\mathrm{i}}$ based on Koop et al. (2000) assuming a nucleation rate of $10^{8} \mathrm{~cm}^{-3} \mathrm{~s}^{-1}$. The vertical dashed black line represents the homogeneous freezing temperature of pure water (HFT). The gold line denotes pore filling of $2.7 \mathrm{~nm}$ wide pores assuming a water contact angle of $\theta=78^{\circ}$. Pores of the hydroxylated and calcined samples are expected to fill well below ice saturation. The dashed salmon lines indicate the required $\mathrm{RH}_{\mathrm{i}}$ for ice to grow to a detectable size within the residence time of ZINC assuming an accommodation coefficient $(\alpha)$ of 0.1 or 0.2 , respectively. Measurements were also conducted at $238 \mathrm{~K}_{\text {, but }}$ an $\mathrm{AF}_{0.05}$ was not detected. The symbols of the calcined and methylated samples are offset by $0.3 \mathrm{~K}$ colder and warmer, respectively, for clarity.

the dry particles that are injected into ZINC reach ice saturation condition within the chamber after about $0.5 \mathrm{~s}$ and water saturation condition after about $1 \mathrm{~s}$ (Stetzer et al., 2008). Thus, there should be enough time for pore water to freeze before equilibrium conditions are reached for those pores that are wide enough to host ice.

At $238 \mathrm{~K}$, the $2.8 \mathrm{~nm}$ samples discussed in this section (2.8H2, 2.8C2 and 2.7M2) do not reach an $\mathrm{AF}_{0.05}$ even above water saturation (Figs. A1d and A2d). Only as the $\mathrm{RH}_{\mathrm{i}}$ approaches and exceeds water saturation do the $\mathrm{AFs}$ of $2.8 \mathrm{H} 2$ and $2.7 \mathrm{M} 2$ reach 0.04 and 0.006 , respectively (Figs. A1d and A2d). The curves of the hydroxylated samples show a weak increase that steepens when water saturation is approached (Fig. A1d), which we ascribe to condensation or immersion freezing (Vali et al., 2015) occurring at active sites on the external particle surface. Pore water is likely not responsible for the observed freezing when the entire particle is immersed in water (Campbell et al., 2015). Furthermore, as temperature increases, the critical ice germ size increases, and therefore, a larger pore diameter is required for PCF to occur at $238 \mathrm{~K}$ than at $233 \mathrm{~K}$, independent of the presence of active sites in the pore. Based on the DSC thermograms shown in Fig. 5a, even the samples with pore diameters of $3.3 \mathrm{~nm}$ have freezing onsets below $238 \mathrm{~K}$. Moreover, $9.1 \mathrm{H} 2$ with pore diameters large enough to accommodate the critical ice embryo based on the DSC measurements (see Fig. 5c) is least efficient at freezing (see Fig. A1d). Therefore, the observed freezing is likely due to nucleation sites on the outer particle surface that become active when immersed in water. This assumption is further substantiated by experiments performed with nonporous silica particles which showed similar ice nucleation activity as their porous counterparts (not shown) at $238 \mathrm{~K}$. The ability of these active sites to nucleate ice is reduced on the methylated sample (see Fig. A2), consistent with previous studies that suggest that hydroxyl groups are important for templating ice formation (Pedevilla et al., 2017) and that alkylated silica surfaces suppress ice nucleation (Kanji et al., 2008). 


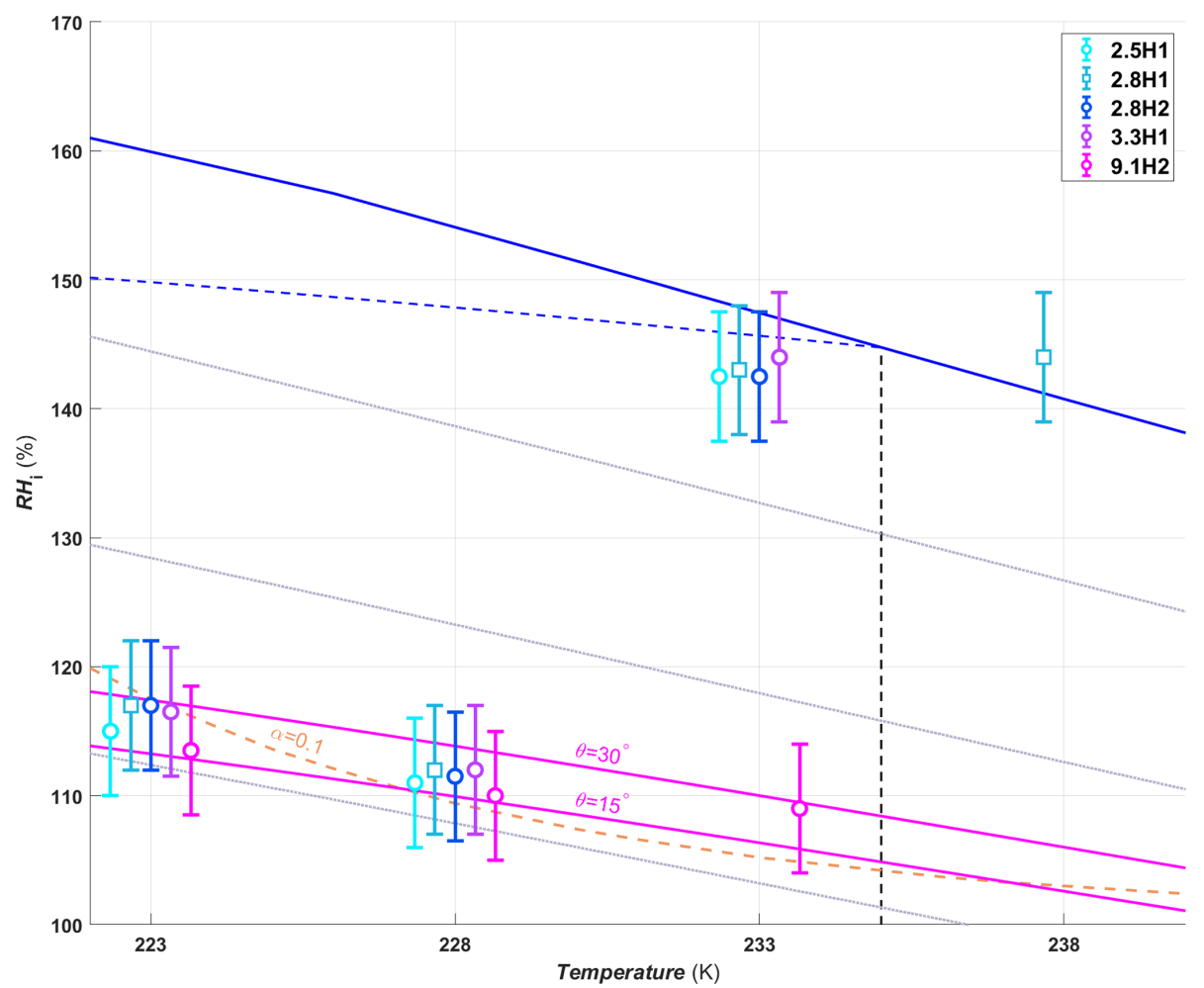

Figure 7. Average $\mathrm{RH}_{\mathrm{i}}$ required to reach an $\mathrm{AF}_{0.05}$ for hydroxylated silica samples of different pore diameters. The symbols are offset by \pm 0.3 or $0.6 \mathrm{~K}$ from the experimental temperatures to make the points more visible. The pore filling lines are plotted for $9.1 \mathrm{~nm}$ pores assuming a water contact angle of 15 and $30^{\circ}$ (magenta lines). Symbols and reference lines are as in Fig. 6.

\subsection{Role of pore diameter on PCF}

In order to investigate the ability of the pore diameter to influence the PCF mechanism, particles with different pore diameters were synthesized with either hydroxyl or trimethylsilyl surface groups, and we discuss these separately in the following.

\subsubsection{Hydroxylated samples}

Pore diameter has no impact on the humidity required for the hydroxylated samples to reach an $\mathrm{AF}_{0.05}$ below the HFT (Fig. 7, dashed back line), the only exception being at $233 \mathrm{~K}$, where ice formation starts well below water saturation for the $9.1 \mathrm{H} 2$ sample, while the smaller pore size samples reach an $\mathrm{AF}_{0.05}$ only close to water saturation. This is indeed expected for pores up to $3.3 \mathrm{~nm}$, when considering that the water contact angle of the pore surface is rather low for the hydroxylated samples $\left(41-45^{\circ}\right.$; see Sect. 3.1 .3$)$, such that the pores are expected to fill already below ice saturation. Assuming that $9.1 \mathrm{H} 2$ has a similar water contact angle as the other hydroxylated samples, the $9.1 \mathrm{~nm}$ pores would require a $\mathrm{RH}_{\mathrm{i}}$ of $\sim 123 \%$ and $118 \%$ at 223 and $228 \mathrm{~K}$, respectively, for pore filling to occur. However, based on the water sorption measurements (see Fig. 4c) the estimated water contact angle of $9.1 \mathrm{H} 2$ is approximately $15^{\circ}$. Furthermore, when ex- amining the pore size distribution shown in Fig. 2d, more than $5 \%$ of the pores are smaller than $9.1 \mathrm{~nm}$ (between 7 and $9 \mathrm{~nm}$ ), and thus, a lower humidity for pore filling is required for these pores. Based on the lower water contact angle alone, the $9.1 \mathrm{~nm}$ pores are expected to fill at $\sim 114 \%$ and $109 \% \mathrm{RH}_{\mathrm{i}}$ at 223 and $228 \mathrm{~K}$, respectively. Therefore, no significant dependence of the $\mathrm{AF}_{0.05}$ is expected for the investigated samples at 223 and $228 \mathrm{~K}$ due to the ice growth limitations in ZINC, as discussed above.

At $233 \mathrm{~K}$ the $\mathrm{AF}_{0.05} \mathrm{RH}_{\mathrm{i}}$ shifts to water saturation for all samples except for $9.1 \mathrm{H} 2$ (Fig. 7). The DSC experiments with 3.3M1 show that ice freezes within the pores only below $233 \mathrm{~K}$ (Fig. 5a). Therefore the inability of $5 \%$ of the particles to freeze up to water saturation for these samples is consistent with PCF.

In contrast, the pore diameters in the $9.1 \mathrm{H} 2$ sample are wide enough to host ice at $233 \mathrm{~K}$ (see DSC experiments, Fig. 5c). Yet, nucleation rates at this temperature are too low for pore water to freeze within the residence time of ZINC. However, the strong increase in the AF at about $108 \%$ $\mathrm{RH}_{\mathrm{i}}$ together with the decrease starting from $125 \% \mathrm{RH}_{\mathrm{i}}$ (see Fig. A1c) can be explained by the dependence of nucleation rates on pressure (Marcolli, 2020). At $233 \mathrm{~K}$, the pressure-dependent version of the Murray et al. (2010) parameterization of CNT (Marcolli, 2020) predicts a nucleation 
rate of $9 \times 10^{10} \mathrm{~cm}^{-3} \mathrm{~s}^{-1}$ at water saturation $(P=0.1 \mathrm{MPa})$, which increases to $2 \times 10^{16} \mathrm{~cm}^{-3} \mathrm{~s}^{-1}$ at the $\mathrm{RH}_{\mathrm{i}}$ of pore filling $\left(\sim 108 \% \mathrm{RH}_{\mathrm{i}}, P=-32 \mathrm{MPa}\right)$. Thus, the water in a pore of $9.1 \mathrm{~nm}$ diameter should freeze at $108 \% \mathrm{RH}_{\mathrm{i}}$ within about $1.6 \mathrm{~s}$. At water saturation, it takes one pore $4 \times 10^{5} \mathrm{~s}$ to freeze, implying that most pores should freeze at $108 \% \mathrm{RH}_{\mathrm{i}}$ within the residence time of ZINC and that the AF decreases when water saturation is approached as can be seen in Fig. Alc.

At $238 \mathrm{~K}$ only the $2.8 \mathrm{H} 1$ sample reached an $\mathrm{AF}_{0.05}$ (Fig. 7). However, all of the other hydroxylated samples with the exception of $9.1 \mathrm{H} 2$, have a similar increase in the $\mathrm{AF}$ near water saturation, reaching values just below the $\mathrm{AF}_{0.05}$ threshold (Fig. A1d). This indicates that there are active sites located on the external particle surface that nucleate ice through immersion or condensation freezing rather than PCF. Considering that pores are closely spaced, the outer surface is cladded in pore openings, providing a nanoscale pattern that might influence the ice nucleation activity in immersion and condensation mode.

The SBA-15 sample 9.1H2 also showed an increase in the AF near water saturation, albeit the increase was about an order of magnitude lower than for the MCM-41 samples (Fig. A1d). Thus, the 9.1H2 surface seems to be less efficient at nucleating ice than the one of the MCM-41 samples, indicating that the synthesis procedure for SBA-15 particles (see Sect. 2.1.1 and 2.1.2) generates less active sites than the one for MCM-41 samples. This is especially true when considering that the pores in the MCM-41 samples are too narrow to host the critical ice embryo, and therefore, the surface area is significantly smaller than for the $9.1 \mathrm{H} 2$ sample. In experiments performed at $243 \mathrm{~K}$ the ability of the hydroxylated samples to nucleate ice approached the detection limit of ZINC and are therefore not shown.

\subsubsection{Methylated samples}

Unlike the hydroxylated samples, the methylated samples show a dependence of onset humidity on pore diameter. At 223 and $228 \mathrm{~K}$, the samples with $2.4 \mathrm{~nm}$ pore diameters had the lowest $\mathrm{AF}_{0.05} \mathrm{RH}_{\mathrm{i}}$ and the $3.3 \mathrm{~nm}$ particles the highest. The 2.6, 2.7 and $9.0 \mathrm{~nm}$ samples are in between and overlap (Fig. 8). This indicates that due to the higher water contact angles after methylation (60-71 $1^{\circ}$ compared with $15-37^{\circ}$ for the hydroxylated samples), PCF is limited by pore filling. Thus, the increase in $\mathrm{RH}_{\mathrm{i}}$ required for filling of increasing pore diameters is observable within ZINC for methylated samples. The similar $\mathrm{AF}_{0.05} \mathrm{RH}_{\mathrm{i}}$ of $9.0 \mathrm{M} 2$ at 223 and $228 \mathrm{~K}$ compared with the methylated MCM-41 samples can be explained by its lower water contact angle $\left(60^{\circ}\right.$ vs. $78^{\circ}$; see Table 1), suggesting a more hydrophilic surface of $9.0 \mathrm{M} 2$ compared with MCM-41. The $9.0 \mathrm{M} 2$ is less active than the 9.1H2 sample (see Figs. 6 and 7), indicating that the methylation and associated increase in water contact angle decreased the ice nucleation ability.
Unlike the hydroxylated samples at $233 \mathrm{~K}$, which showed a clear increase in the $\mathrm{AF}$ at $\sim 105 \% \mathrm{RH}_{\mathrm{i}}$ (Fig. A1c), the methylated samples (except 9.0M2) show only a weak and continuous increase in the AF up to approximately 0.01 before water saturation is reached and homogeneous freezing of bulk water sets in (see Fig. A2c). This difference is likely due to the higher humidity required for pore filling of the methylated samples. The pore water experiences just a moderately negative pressure of at most $-26 \mathrm{MPa}$ at pore filling conditions, which enhances nucleation rates to a level that is able to induce freezing in only very few pores that also need to be wide enough to host ice. The reduction in the AF below water saturation of the methylated compared with the hydroxylated samples is consistent with previous observations that alkylation of silanol groups suppressed ice nucleation below water saturation at $233 \mathrm{~K}$ (Kanji et al., 2008).

The $\mathrm{AF}_{0.05}$ of $9.0 \mathrm{M} 2$ is close to the predicted pore filling line for $\theta=78^{\circ}$ at $233 \mathrm{~K}$ (Fig. 8), while at 223 and $228 \mathrm{~K}$, it is much below the predicted line even for $\theta=60^{\circ}$. This freezing activity is attributed to either nonuniform methylation, which led to variations in water contact angle, or the presence of pore-like imperfections on the rough surface of the $9.0 \mathrm{M} 2$ particles that are narrower than the measured pore diameters and remained undetected in the pore-size distribution (Fig. 2) due to their extremely small volumes. At $233 \mathrm{~K}$, the onset humidity of the $2.7 \mathrm{M} 2$ shifts close to water saturation in accordance with the DSC results in Fig. 5 showing that ice only freezes close to or below $233 \mathrm{~K}$ for pores narrower than $3.3 \mathrm{~nm}$ (see Fig. A2). A clear onset $\mathrm{RH}_{\mathrm{i}}$ where the bulk of the 9.0M2 particles nucleate ice is absent (Fig. A2c) as is observed with $9.1 \mathrm{H} 2$ in Fig. A1c, indicating that pores of $9.0 \mathrm{M} 2$ continuously fill and freeze while $\mathrm{RH}$ increases. Indeed, the measured pore diameters by $\mathrm{N}_{2}$ sorption (see Fig. 2d) show a wide pore size distribution for $9.0 \mathrm{M} 2$ and 9.1H2. Water uptake reaching $1 \mathrm{wt} \%$ only above $90 \% \mathrm{RH}_{\mathrm{w}}$ for 9.0M2 (Fig. 4) is in accordance with AF exceeding 0.05 only for $\mathrm{RH}_{\mathrm{i}}>130 \%$, further supporting that ice nucleation on $9.0 \mathrm{M} 2$ is limited by pore filling. Since homogeneous nucleation rates close to water saturation at $233 \mathrm{~K}$ are rather too low to induce freezing of water in $9.0 \mathrm{M} 2$ pores, ice nucleation sites for immersion freezing within the pores might be responsible for the observed AF. The assumption of nucleation sites on the $9.0 \mathrm{M} 2$ is further supported by its ice nucleation activity persisting above the HFT (Fig. A2d).

The methylated MCM-41 samples have a very weak increase in the AF around water saturation at $238 \mathrm{~K}$ (Fig. A2d), reaching a similar $\mathrm{AF}$ as at $233 \mathrm{~K}$ below water saturation. The increase in the AF for MCM- 41 samples at $238 \mathrm{~K}$ is lower than the one observed for the hydroxylated MCM-41 samples at the same temperatures and relative humidities, consistent with the notion that methylation decreases the ice nucleation activity of a surface (Kanji et al., 2008).

At $238 \mathrm{~K}$, the $9.0 \mathrm{M} 2$ sample shows a distinct and continuous increase in the AF below water saturation. Since the temperature is too high for homogeneous ice nucleation 


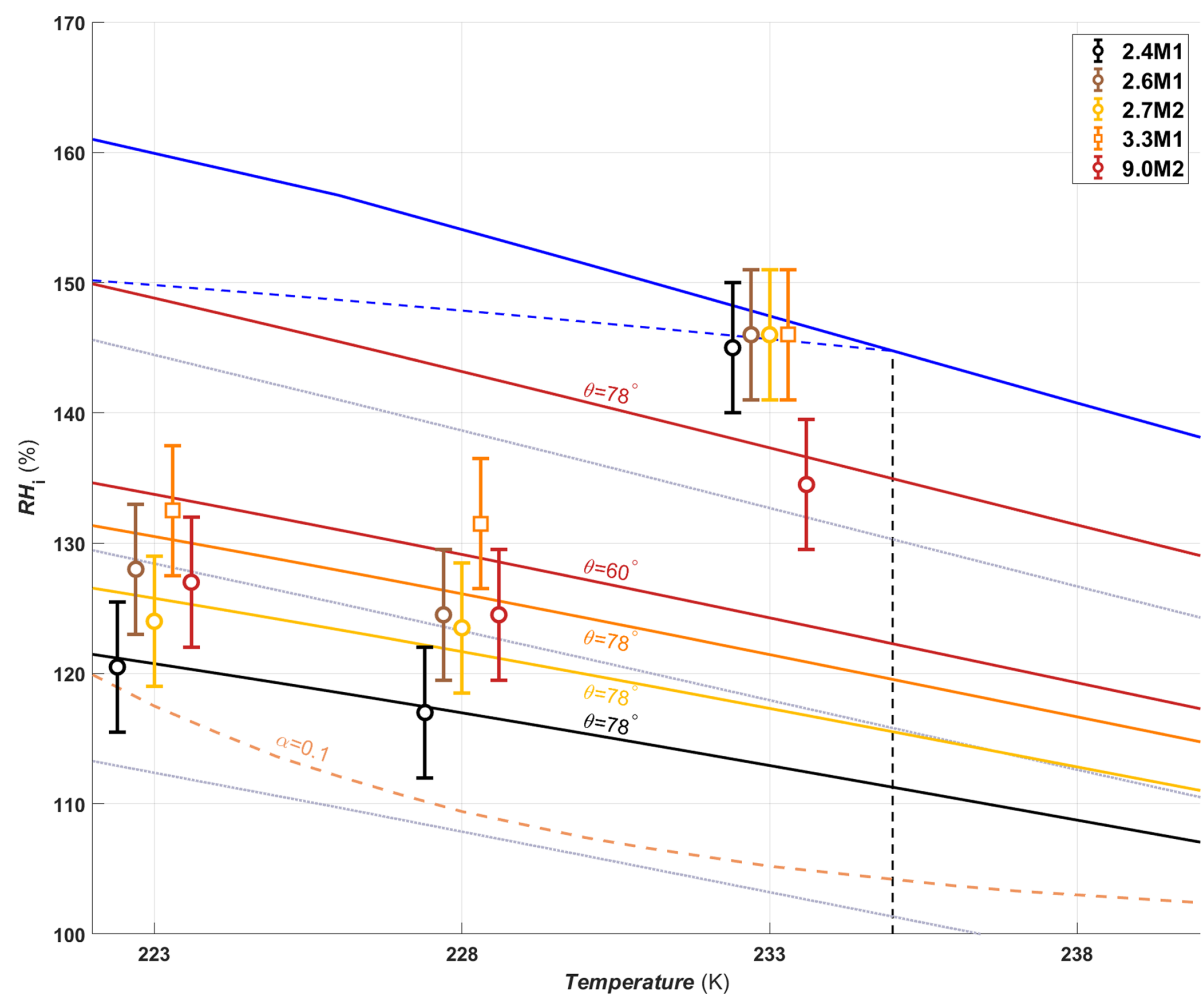

Figure 8. Average $\mathrm{RH}_{\mathrm{i}}$ required to reach an $\mathrm{AF}_{0.05}$ for methylated silica samples of different pore diameters. The symbols are offset by \pm 0.3 or $0.6 \mathrm{~K}$ from the experimental temperatures to make the points more visible. Pore filling lines are given for 2.4 (black line), 2.7 (gold line) and $3.3 \mathrm{~nm}$ (orange line) pores assuming a water contact angle of $78^{\circ}$. For $9.0 \mathrm{~nm}$ pores the pore filling lines are plotted assuming water contact angles of 60 and $78^{\circ}$ (red lines).

within pores, this is a clear indication of active sites present in pores resulting in immersion freezing as soon as the pores fill with water. Interestingly, the AF is higher in $9.0 \mathrm{M} 2 \mathrm{com}-$ pared with 9.1H2 (Figs. A2d and A1d, respectively), showing that the density of hydroxyl groups is not always a good predictor for ice nucleation ability. Indeed, it has been shown that methylated amorphous silica has an enhanced nucleation ability relative to hydroxylated silica due to the condensation of water on a hydrophilic $\mathrm{Si}-\mathrm{OH}$ group surrounded by methylated groups (Bassett et al., 1970; Salazar and Sepúlveda, 1983). Salazar and Sepúlveda (1983) postulated that adsorption on islands of silanol groups followed by multilayer growth similar to condensation of water would nucleate ice when water molecules come in contact with the neighboring methyl groups. However, it is important to note that hydroxylation and methylation had an opposite effect on the heterogeneous ice nucleation ability at $238 \mathrm{~K}$ of MCM-41 and SBA-15 particles, making generalization in terms of dependence on water contact angle and degree of hydroxylation difficult. The MCM-41 samples are spherical (Fig. 1a and b), and the pore entrances are evenly distributed over the entire particle surface. Meanwhile, the SBA-15 samples are hexagonal and consist of a 2-D network of pores oriented along the long axis of their geometry (Fig. 1c and d) and, thus, poten- tially have six pore-free faces where the interaction between silanol islands and surrounding trimethylsilyl groups is possible. Thus, the potential presence of nonporous faces on the SBA-15 samples could explain the difference in the role of methylation and hydroxylation on the heterogeneous freezing abilities of the sample types at $238 \mathrm{~K}$.

\section{Summary and conclusion}

In this study we have investigated the mechanism of pore condensation and freezing and its dependence on pore diameter and water contact angle using synthesized silica particles with well-defined pore diameters. Particle wettability/water contact angle was systematically varied through functionalizing the silica particles with hydroxyl and trimethylsilyl surface groups. The functionalized particles were characterized by $\mathrm{N}_{2}$ and water vapor sorption, DRIFTS and DSC measurements. Ice nucleation experiments on the porous particles were performed in a continuous-flow diffusion chamber, covering a $T$ range of $223-238 \mathrm{~K}$ and a relative humidity range of $100 \% \mathrm{RH}_{\mathrm{i}}$ to $105 \% \mathrm{RH}_{\mathrm{w}}$, and observed ice nucleation was compared to that predicted by PCF.

The experiments show that the presence of pores together with their diameters and water contact angle are good predic- 
tors for the ice nucleation ability of particles below the HFT and below water saturation. The PCF mechanism framework accurately predicts ice nucleation at these conditions. Furthermore, the observed ice nucleation below the HFT did not support a so-called two-step nucleation process confirming our previous observations using similar particle types (David et al., 2019).

Above the HFT, ice nucleation within pores cannot occur homogeneously; instead rare active sites can promote heterogeneous nucleation resulting in a lower probability of ice nucleation compared to PCF at $T<$ HFT. Therefore, above the HFT, porosity is no longer a predictor for ice nucleation, and the observed ice nucleation activity needs to be explained by the surface functionalization i.e., hydroxylation or methylation and the associated presence of so-called active sites. The enhancement in freezing due to the presence of hydroxyl or methyl groups depended on the sample type, with hydroxylated surfaces enhancing ice nucleation on the MCM-41 particles (spherical particles with pore diameters $2.4-3.3 \mathrm{~nm}$ ) and methylation enhancing ice nucleation in the presence of SBA-15 particles (nonspherical of $\sim 9 \mathrm{~nm}$ pore diameter). Although the two particle types are composed of the same material, silica, the differing effect of the functional groups indicates that the role of functional groups depends on the specific surface structure. Ice nucleation at $238 \mathrm{~K}$ mainly occurred at water saturation, indicating that immersion or condensation freezing was the responsible mechanism.
In summary, the ability of particles to nucleate ice below water saturation in cirrus conditions can be predicted by the particle pore size distribution and water contact angle. Therefore, ice nucleation parameterizations should include the PCF mechanism below the HFT. Above the HFT, active sites present on the particle surface determine the ice nucleation activity at water saturation, while below water saturation, active sites within pores are required to nucleate ice. In the troposphere, mineral dust particles, which are generally hydrophilic with low water contact angles, will nucleate ice via PCF, and the extent of which will depend on factors such as pore size distribution and shape, water contact angle, and any coatings on the dust particles. Therefore, we recommend that future studies should focus on characterizing particle porosity and water contact angle to better assess the role of pores on ice nucleation. We also recommend that future studies investigate the role of atmospheric aging and coatings on PCF. Certain coatings can lower the freezing point of pore water or completely block pores, inhibiting particles from nucleating ice. Thus, understanding the role of atmospheric aging on the ability of porous particles to nucleate ice via PCF is essential for understanding how anthropogenic emissions, such as soot, which has been shown to nucleate ice in accordance with PCF (Mahrt et al., 2018, 2020a, b; Nichman et al., 2019), will impact future climate. 


\section{Appendix A}

\section{A1}

The volume of water required to hydroxylate the particles $\left(V_{\mathrm{w}}\right)$ was calculated as

$V_{\mathrm{w}}=\frac{m_{\mathrm{SiO}_{2}} \cdot A_{\mathrm{s}} \cdot \sigma_{\mathrm{SiOH}} \cdot M_{\mathrm{w}}}{\rho_{W} \cdot N_{\mathrm{A}}}$,

where $m_{\mathrm{SiO}_{2}}$ is the mass of silica particles, $A_{\mathrm{S}}$ is the specific surface area of the silica particles, $\sigma_{\mathrm{SiOH}}=4.6 \mathrm{~nm}^{-2}$ is the desired concentration of surface silanol groups following (Zhuralev, 2000), $M_{\mathrm{w}}$ is the molar mass of water, $\rho_{\mathrm{w}}$ is the density of water and $N_{\mathrm{A}}$ is the Avogadro constant. The amount of organosilane added to methylate the particles was calculated following Eq. (A1) except that $M_{O}$ and $\rho_{O}$ are molar mass and the density of the respective organosilane.

$V_{O}=\frac{m_{\mathrm{SiO}_{2}} \cdot A_{\mathrm{s}} \cdot \sigma_{\mathrm{SiOH}} \cdot M_{O}}{\rho_{O} \cdot N_{\mathrm{A}}}$

The AF curves of the hydroxylated and methylated samples are shown in Figs. A1 and A2.

\section{A2}

Ice crystal growth in ZINC for a given residence time $(t)$, supersaturation with respect to ice $\left(S_{\mathrm{i}}\right)$ and temperature $(T)$ was calculated based on Rogers and Yau (1989) and Lohmann et al. (2016) as follows:

$r\left(t, S_{\mathrm{i}}, T\right)=\sqrt{r_{0}^{2}+2 \alpha\left(\frac{S_{\mathrm{i}}-1}{F_{k}+F_{D}}\right) t}$,

where $r\left(t, S_{\mathrm{i}}, T\right)$ is the final radius of a spherical ice crystal. A spherical assumption for ice crystals is based on the small size of the ice crystals detected in this study $(\sim 1 \mu \mathrm{m})$ and the fact that the ice is growing on spherical particles (Harrington et al., 2019). $r_{0}$ represents the original radius of the silica particles $(400 \mathrm{~nm})$ and is squared in the equation to account for the capacitance, which for spherical particles is equal to its radius (Rogers and Yau, 1989). $\alpha$ is the accommodation coefficient for water molecules to be incorporated into an ice lattice, which has been observed as ranging between 0.004 and 0.1 for the temperatures investigated in this study (Earle et al., 2010; Isono and Iwai, 1969; Magee et al., 2006; Skrotzki et al., 2013) and are chosen as 0.1 and 0.2 in this study. The terms in the denominator of Eq. (A3) are

$F_{k}=\left(\frac{L_{\mathrm{s}}}{R_{v} T}-1\right) \frac{L_{\mathrm{s}}}{K T}$,

where $L_{\mathrm{S}}$ is the latent heat of sublimation as parameterized by Murphy and Koop (2005), $R_{v}$ is the moist gas constant and $K$ represents the thermal conductivity coefficient taken from Beard and Pruppacher (1971).
$F_{D}=\frac{R_{v} T}{D_{\mathrm{v}} e_{\mathrm{s}, \mathrm{i}}(T)}$

Here the water vapor diffusion coefficient in air $\left(D_{\mathrm{v}}\right)$ was taken from Hall and Pruppacher (1976) and $e_{\mathrm{s}, \mathrm{i}}(T)$ is the ice saturation vapor pressure as parameterized in Murphy and Koop (2005).

For each experimental temperature, the $S_{\mathrm{i}}$ required for a crystal to grow to $1 \mu \mathrm{m}$, the ice threshold in the OPC, is calculated by reorganizing Eq. (A3) and using a residence time of $10 \mathrm{~s}$. 

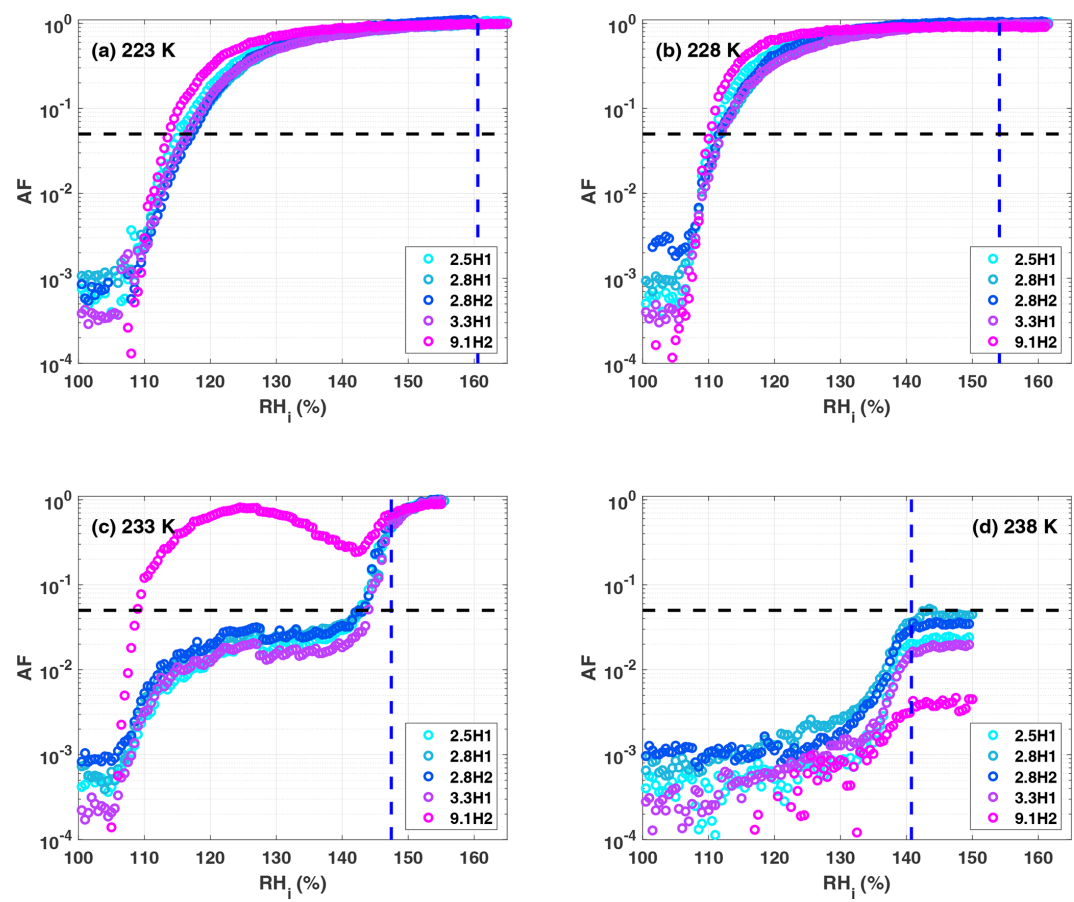

Figure A1. Activated fraction (AF) curves for the hydroxylated samples as a function of $\mathrm{RH}_{\mathrm{i}}$ at (a) $223 \mathrm{~K}$, (b) $228 \mathrm{~K}$, (c) $233 \mathrm{~K}$ and (d) $238 \mathrm{~K}$. The blue dashed vertical line represents the $\mathrm{RH}_{\mathrm{i}}$ corresponding to water saturation. The black dashed horizontal line indicates the $\mathrm{AF}_{0.05}$ threshold. The decrease in the AF for the $9.1 \mathrm{H} 2$ sample (magenta circles) in panel (c) was reproducible but disappeared at $231 \mathrm{~K}$ (not shown).
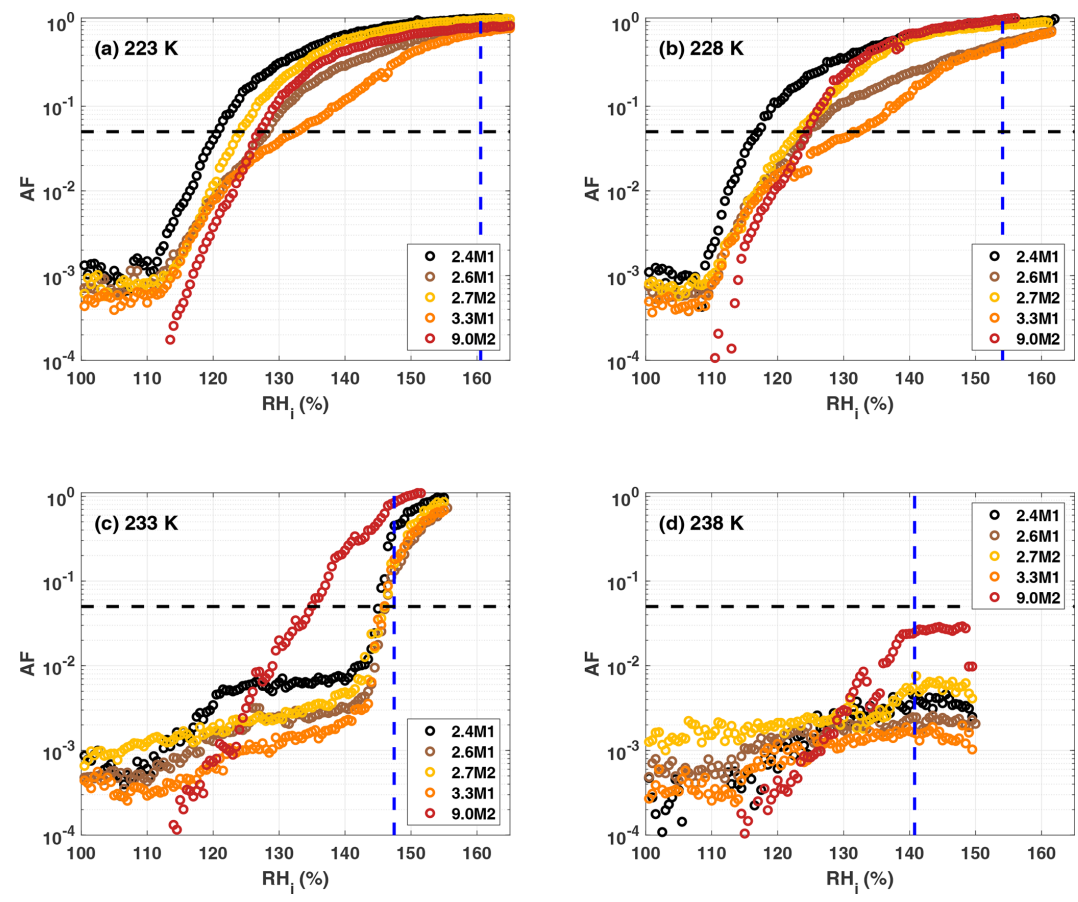

Figure A2. Activated fraction (AF) curves for the methylated samples as a function of $\mathrm{RH}_{\mathrm{i}}$ at (a) $223 \mathrm{~K}$, (b) $228 \mathrm{~K}$, (c) $233 \mathrm{~K}$ and (d) $238 \mathrm{~K}$. The blue dashed vertical line represents the $\mathrm{RH}_{\mathrm{i}}$ corresponding to water saturation. The black dashed horizontal line indicates the $\mathrm{AF}_{0.05}$ threshold. 
Data availability. The data presented in this publication are available at the following DOI: https://doi.org/10.3929/ethz-b000420623, David et al. (2020).

Author contributions. ROD wrote the article with contributions from CM, ZAK, JF and FM. ROD conducted the ice nucleation measurements with help from FM. ROD analyzed the ice nucleation data. JF and DB synthesized and characterized the particles with varying pore diameters and functional groups. ROD interpreted the data with assistance from CM and ZAK. CM and ZAK supervised the project.

Competing interests. The authors declare that they have no conflict of interest.

Acknowledgements. We would like to thank Hannes Wydler for all of his technical assistance during this project. We would also like to thank Lukas Huber at EMPA Dübendorf for performing the water sorption measurements. Robert O. David, Zamin A. Kanji, Dominik Brühwiler and Jonas Fahrni acknowledge support for this work from SNF grant no. 200021_156581.

Financial support. This research has been supported by the Swiss National Science Foundation (grant no. 200021_156581).

Review statement. This paper was edited by Thorsten BartelsRausch and reviewed by two anonymous referees.

\section{References}

Atkinson, J. D., Murray, B. J., and O'Sullivan, D.: Rate of Homogenous Nucleation of Ice in Supercooled Water, J. Phys. Chem. A, 120, 6513-6520, https://doi.org/10.1021/acs.jpca.6b03843, 2016.

Bartels-Rausch, T., Jacobi, H.-W., Kahan, T. F., Thomas, J. L., Thomson, E. S., Abbatt, J. P. D., Ammann, M., Blackford, J. R., Bluhm, H., Boxe, C., Domine, F., Frey, M. M., Gladich, I., Guzmán, M. I., Heger, D., Huthwelker, Th., Klán, P., Kuhs, W. F., Kuo, M. H., Maus, S., Moussa, S. G., McNeill, V. F., Newberg, J. T., Pettersson, J. B. C., Roeselová, M., and Sodeau, J. R.: A review of air-ice chemical and physical interactions (AICI): liquids, quasi-liquids, and solids in snow, Atmos. Chem. Phys., 14, 1587-1633, https://doi.org/10.5194/acp-14-1587-2014, 2014.

Bassett, D. R., Boucher, E. A., and Zettlemoyer, A. C.: Adsorption studies on ice-nucleating substrates. Hydrophobed silicas and silver iodide, J. Colloid Interf. Sci., 34, 436-446, https://doi.org/10.1016/0021-9797(70)90203-1, 1970.

Beard, K. V. and Pruppacher, H. R.: A Wind Tunnel Investigation of the Rate of Evaporation of Small Water Drops Falling at Terminal Velocity in Air, J. Atmos. Sci., 28, 1455-1464, https://doi.org/10.1175/15200469(1971)028<1455:AWTIOT>2.0.CO;2, 1971.
Beck, J. S., Vartuli, J. C., Roth, W. J., Leonowicz, M. E., Kresge, C. T., Schmitt, K. D., Chu, C. T. W., Olson, D. H., Sheppard, E. W., and McCullen, S. B.: A new family of mesoporous molecular sieves prepared with liquid crystal templates, J. Am. Chem. Soc., 114, 10834-10843, 1992.

Bergna, H. E.: Colloid Chemistry of Silica, in: The Colloid Chemistry of Silica, Advances in Chemistry, vol. 234, American Chemical Society, Washington DC, 1-47, https://doi.org/10.1021/ba-1994-0234.ch001, 1994.

Bhambhani, M. R., Cutting, P. A., Sing, K. S. W., and Turk, D. H.: Analysis of nitrogen adsorption isotherms on porous and nonporous silicas by the BET and $\alpha$ s methods, J. Colloid Interf. Sci., 38, 109-117, https://doi.org/10.1016/0021-9797(72)902263, 1972.

Boose, Y., Kanji, Z. A., Kohn, M., Sierau, B., Zipori, A., Crawford, I., Lloyd, G., Bukowiecki, N., Herrmann, E., Kupiszewski, P., Steinbacher, M., and Lohmann, U.: Ice Nucleating Particle Measurements at $241 \mathrm{~K}$ during Winter Months at 3580 $\mathrm{m}$ MSL in the Swiss Alps, J. Atmos. Sci., 73, 2203-2228, https://doi.org/10.1175/JAS-D-15-0236.1, 2016.

Broekhoff, J. C. P. and de Boer, J. H.: Studies on pore systems in catalysts: IX. Calculation of pore distributions from the adsorption branch of nitrogen sorption isotherms in the case of open cylindrical pores A. Fundamental equations, J. Catal., 9, 8-14, https://doi.org/10.1016/0021-9517(67)90174-1, 1967.

Brunauer, S., Emmett, P. H., and Teller, E.: Adsorption of gases in multimolecular layers, J. Am. Chem. Soc., 60, 309-319, 1938.

Burkert-Kohn, M., Wex, H., Welti, A., Hartmann, S., Grawe, S., Hellner, L., Herenz, P., Atkinson, J. D., Stratmann, F., and Kanji, Z. A.: Leipzig Ice Nucleation chamber Comparison (LINC): intercomparison of four online ice nucleation counters, Atmos. Chem. Phys., 17, 11683-11705, https://doi.org/10.5194/acp-1711683-2017, 2017.

Campbell, J. M. and Christenson, H. K.: Nucleation- and Emergence-Limited Growth of Ice from Pores, Phys. Rev. Lett., 120, 165701, https://doi.org/10.1103/PhysRevLett.120.165701, 2018.

Campbell, J. M., Meldrum, F. C., and Christenson, H. K.: Is Ice Nucleation from Supercooled Water Insensitive to Surface Roughness?, J. Phys. Chem. C, 119, 1164-1169, https://doi.org/10.1021/jp5113729, 2015.

Campbell, J. M., Meldrum, F. C., and Christenson, H. K.: Observing the formation of ice and organic crystals in active sites, P. Natl Acad. Sci. USA, 114, 810-815, 2017.

Chen, J., Li, Q., Xu, R., and Xiao, F.: Distinguishing the Silanol Groups in the Mesoporous Molecular Sieve MCM-41, Angew. Chem. Int. Ed., 34, 2694-2696, https://doi.org/10.1002/anie.199526941, 1996.

Christenson, H. K.: Two-step crystal nucleation via capillary condensation, CrystEngComm, 15, 2030, https://doi.org/10.1039/c3ce26887j, 2013.

Cooper, W. A.: A Possible Mechanism for Contact Nucleation, J. Atmos. Sci., 31, 1832-1837, https://doi.org/10.1175/15200469(1974)031<1832:APMFCN>2.0.CO;2, 1974.

David, R. O., Marcolli, C., Fahrni, J., Qiu, Y., Sirkin, Y. A. P., Molinero, V., Mahrt, F., Brühwiler, D., Lohmann, U., and Kanji, Z. A.: Pore condensation and freezing is responsible for ice formation below water saturation for 
porous particles, P. Natl. Acad. Sci. USA, 116, 8184-8189, https://doi.org/10.1073/pnas.1813647116, 2019.

David, R. O., Fahrni, J., Marcolli, C., Mahrt, F., Brühwiler, D., and Kanji, Z. A.: The Role of Contact Angle and Pore Width on Pore Condensation and Freezing, ETH Zurich, https://doi.org/10.3929/ethz-b-000420623, 2020.

Deschamps, J., Audonnet, F., Brodie-Linder, N., Schoeffel, M., and Alba-Simionesco, C.: A thermodynamic limit of the melting/freezing processes of water under strongly hydrophobic nanoscopic confinement, Phys. Chem. Chem. Phys., 12, 14401443, https://doi.org/10.1039/B920816J, 2010.

Earle, M. E., Kuhn, T., Khalizov, A. F., and Sloan, J. J.: Volume nucleation rates for homogeneous freezing in supercooled water microdroplets: results from a combined experimental and modelling approach, Atmos. Chem. Phys., 10, 7945-7961, https://doi.org/10.5194/acp-10-7945-2010, 2010.

Findenegg, G. H., Jähnert, S., Akcakayiran, D., and Schreiber, A.: Freezing and Melting of Water Confined in Silica Nanopores, ChemPhysChem, 9, 2651-2659, https://doi.org/10.1002/cphc.200800616, 2008.

Fletcher, N. H.: The physics of rainclouds, Cambridge University Press, Cambridge, UK, ISBN 978-0-521-05013-5, 1962.

Fletcher, N. H.: Active Sites and Ice Crystal Nucleation, J. Atmos. Sci., 26, 1266-1271, https://doi.org/10.1175/15200469(1969)026<1266:ASAICN>2.0.CO;2, 1969.

Fukuta, N.: Activation of Atmospheric Particles as Ice Nuclei in Cold and Dry Air, J. Atmos. Sci., 23, 741-750, https://doi.org/10.1175/15200469(1966)023<0741:AOAPAI>2.0.CO;2, 1966.

Garimella, S., Rothenberg, D. A., Wolf, M. J., David, R. O., Kanji, Z. A., Wang, C., Rösch, M., and Cziczo, D. J.: Uncertainty in counting ice nucleating particles with continuous flow diffusion chambers, Atmos. Chem. Phys., 17, 10855-10864, https://doi.org/10.5194/acp-17-10855-2017, 2017.

Hall, W. D. and Pruppacher, H. R.: The Survival of Ice Particles Falling from Cirrus Clouds in Subsaturated Air, J. Atmos. Sci., 33, 1995-2006, https://doi.org/10.1175/15200469(1976)033<1995:TSOIPF>2.0.CO;2, 1976.

Hamadeh, I. M., Yeboah, S. A., Trumbull, K. A., and Griffiths, P. R.: Preparation of Calibration Standards for Quantitative Diffuse Reflectance Infrared Spectrometry, Appl. Spectrosc., 38, 486-491, 1984.

Harrington, J. Y., Moyle, A., Hanson, L. E., and Morrison, H.: On Calculating Deposition Coefficients and Aspect-Ratio Evolution in Approximate Models of Ice Crystal Vapor Growth, J. Atmos. Sci., 76, 1609-1625, https://doi.org/10.1175/JAS-D-18-0319.1, 2019.

Higuchi, K. and Fukuta, N.: Ice in the Capillaries of Solid Particles and its Effect on their Nucleating Ability, J. Atmos. Sci., 23, 187-190, https://doi.org/10.1175/15200469(1966)023<0187:IITCOS>2.0.CO;2, 1966.

Ickes, L., Welti, A., Hoose, C., and Lohmann, U.: Classical nucleation theory of homogeneous freezing of water: thermodynamic and kinetic parameters, Phys. Chem. Chem. Phys. PCCP, 17, 5514-5537, https://doi.org/10.1039/c4cp04184d, 2015.

Isono, K. and Iwai, K.: Growth Mode of Ice Crystals in Air at Low Pressure, Nature, 22, 1149-1150, https://doi.org/10.1038/2231149a0, 1969.
Jähnert, S., Vaca Chávez, F., Schaumann, G. E., Schreiber, A., Schönhoff, M., and Findenegg, G. H.: Melting and freezing of water in cylindrical silica nanopores, Phys. Chem. Chem. Phys., 10, 6039, https://doi.org/10.1039/b809438c, 2008.

Janssen, A. H., Talsma, H., van Steenbergen, M. J., and de Jong, K. P.: Homogeneous Nucleation of Water in Mesoporous Zeolite Cavities, Langmuir, 20, 41-45, https://doi.org/10.1021/la034340k, 2004.

Jelassi, J., Castricum, H. L., Bellissent-Funel, M.-C., Dore, J., Webber, J. B. W., and Sridi-Dorbez, R.: Studies of water and ice in hydrophilic and hydrophobic mesoporous silicas: pore characterisation and phase transformations, Phys. Chem. Chem. Phys., 12, 2838-2849, https://doi.org/10.1039/B908400B, 2010.

Kanji, Z. A., Florea, O., and Abbatt, J. P. D.: Ice formation via deposition nucleation on mineral dust and organics: dependence of onset relative humidity on total particulate surface area, Environ. Res. Lett., 3, 025004, https://doi.org/10.1088/17489326/3/2/025004, 2008.

Kanji, Z. A., Welti, A., Chou, C., Stetzer, O., and Lohmann, U.: Laboratory studies of immersion and deposition mode ice nucleation of ozone aged mineral dust particles, Atmos. Chem. Phys., 13, 9097-9118, https://doi.org/10.5194/acp-139097-2013, 2013.

Kaufmann, L., Marcolli, C., Luo, B., and Peter, T.: Refreeze experiments with water droplets containing different types of ice nuclei interpreted by classical nucleation theory, Atmos. Chem. Phys., 17, 3525-3552, https://doi.org/10.5194/acp-173525-2017, 2017.

Ketcham, W. M. and Hobbs, P. V.: An experimental determination of the surface energies of ice, Philos. Mag., 19, 1161-1173, https://doi.org/10.1080/14786436908228641, 1969.

Kiselev, A., Bachmann, F., Pedevilla, P., Cox, S. J., Michaelides, A., Gerthsen, D., and Leisner, T.: Active sites in heterogeneous ice nucleation - the example of K-rich feldspars, Science, 355, 367-371, https://doi.org/10.1126/science.aai8034, 2017.

Kittaka, S., Ueda, Y., Fujisaki, F., Iiyama, T., and Yamaguchi, T.: Mechanism of freezing of water in contact with mesoporous silicas MCM-41, SBA-15 and SBA-16: role of boundary water of pore outlets in freezing, Phys. Chem. Chem. Phys., 13, 17222, https://doi.org/10.1039/c1cp21458f, 2011.

Kocherbitov, V. and Alfredsson, V.: Hydration of MCM-41 Studied by Sorption Calorimetry, J. Phys. Chem. C, 111, 12906-12913, https://doi.org/10.1021/jp072474r, 2007.

Koop, T.: Crystals creeping out of cracks, P. Natl. Acad. Sci. USA, 114, 797-799, https://doi.org/10.1073/pnas.1620084114, 2017.

Koop, T. and Murray, B. J.: A physically constrained classical description of the homogeneous nucleation of ice in water, J. Chem. Phys., 145, 211915, https://doi.org/10.1063/1.4962355, 2016.

Koop, T., Luo, B., Tsias, A., and Peter, T.: Water activity as the determinant for homogeneous ice nucleation in aqueous solutions, Nature, 406, 611-614, https://doi.org/10.1038/35020537, 2000.

Kovács, T. and Christenson, H. K.: A two-step mechanism for crystal nucleation without supersaturation, Faraday Discuss., 159, 123-138, https://doi.org/10.1039/C2FD20053H, 2012.

Kovács, T., Meldrum, F. C., and Christenson, H. K.: Crystal Nucleation without Supersaturation, J. Phys. Chem. Lett., 3, 16021606, https://doi.org/10.1021/jz300450g, 2012.

Kruk, M., Jaroniec, M., and Sayari, A.: Application of Large Pore MCM-41 Molecular Sieves To Improve Pore Size Analysis Us- 
ing Nitrogen Adsorption Measurements, Langmuir, 13, 62676273, https://doi.org/10.1021/la970776m, 1997.

Kuhs, W. F., Sippel, C., Falenty, A., and Hansen, T. C.: Extent and relevance of stacking disorder in "ice Ic," P. Natl. Acad. Sci. USA, 109, 21259-21264, https://doi.org/10.1073/pnas.1210331110, 2012.

Kumar, A., Marcolli, C., Luo, B., and Peter, T.: Ice nucleation activity of silicates and aluminosilicates in pure water and aqueous solutions - Part 1: The K-feldspar microcline, Atmos. Chem. Phys., 18, 7057-7079, https://doi.org/10.5194/acp18-7057-2018, 2018.

Landers, J., Gor, G. Yu., and Neimark, A. V.: Density functional theory methods for characterization of porous materials, Colloid. Surface. A, 437, 3-32, https://doi.org/10.1016/j.colsurfa.2013.01.007, 2013.

Linton, P., Rennie, A. R., Zackrisson, M., and Alfredsson*, V.: In Situ Observation of the Genesis of Mesoporous Silica SBA-15: Dynamics on Length Scales from $1 \mathrm{~nm}$ to $1 \mu \mathrm{m}$, Langmuir, 25, 4685-4691, https://doi.org/10.1021/la803543z, 2009a.

Linton, P., Hernandez-Garrido, J.-C., Midgley, P. A., Wennerström, H., and Alfredsson, V.: Morphology of SBA-15-directed by association processes and surface energies, Phys. Chem. Chem. Phys., 11, 10973-10982, https://doi.org/10.1039/B913755F, 2009b.

Lohmann, U., Lüönd, F., and Mahrt, F.: An Introduction to Clouds: From the Microscale to Climate, Cambridge University Press, Cambridge, https://doi.org/10.1017/CBO9781139087513, 2016.

Lupi, L., Hudait, A., Peters, B., Grünwald, M., Mullen, R. G., Nguyen, A. H., and Molinero, V.: Role of stacking disorder in ice nucleation, Nature, 551, 218-222, https://doi.org/10.1038/nature24279, 2017.

Magee, N., Moyle, A. M., and Lamb, D.: Experimental determination of the deposition coefficient of small cirruslike ice crystals near $-50^{\circ} \mathrm{C}$, Geophys. Res. Lett., 33, https://doi.org/10.1029/2006GL026665, 2006.

Mahrt, F., Marcolli, C., David, R. O., Grönquist, P., Barthazy Meier, E. J., Lohmann, U., and Kanji, Z. A.: Ice nucleation abilities of soot particles determined with the Horizontal Ice Nucleation Chamber, Atmos. Chem. Phys., 18, 13363-13392, https://doi.org/10.5194/acp-18-13363-2018, 2018.

Mahrt, F., Alpert, P. A., Dou, J., Grönquist, P., Arroyo, P. C., Ammann, M., Lohmann, U., and Kanji, Z. A.: Aging induced changes in ice nucleation activity of combustion aerosol as determined by near edge X-ray absorption fine structure (NEXAFS) spectroscopy, Environ. Sci.-Proc. Imp., 22, 895-907, https://doi.org/10.1039/C9EM00525K, 2020a.

Mahrt, F., Kilchhofer, K., Marcolli, C., Grönquist, P., David, R. O., Rösch, M., Lohmann, U., and Kanji, Z. A.: The Impact of Cloud Processing on the Ice Nucleation Abilities of Soot Particles at Cirrus Temperatures, J. Geophys. Res.-Atmos., 125, e2019JD030922, https://doi.org/10.1029/2019JD030922, 2020 b.

Malkin, T. L., J. Murray, B., G. Salzmann, C., Molinero, V., J. Pickering, S., and F. Whale, T.: Stacking disorder in ice I, Phys. Chem. Chem. Phys., 17, 60-76, https://doi.org/10.1039/C4CP02893G, 2015.

Marcolli, C.: Deposition nucleation viewed as homogeneous or immersion freezing in pores and cavities, Atmos. Chem. Phys., 14, 2071-2104, https://doi.org/10.5194/acp-14-2071-2014, 2014.
Marcolli, C.: Technical note: Fundamental aspects of ice nucleation via pore condensation and freezing including Laplace pressure and growth into macroscopic ice, Atmos. Chem. Phys., 20, 3209 3230, https://doi.org/10.5194/acp-20-3209-2020, 2020.

Marcolli, C., Gedamke, S., Peter, T., and Zobrist, B.: Efficiency of immersion mode ice nucleation on surrogates of mineral dust, Atmos. Chem. Phys., 7, 5081-5091, https://doi.org/10.5194/acp7-5081-2007, 2007.

McFarquhar, G. M., Baumgardner, D., and Heymsfield, A. J.: Background and Overview, Meteor. Mon., 58, v-ix, https://doi.org/10.1175/AMSMONOGRAPHS-D-16-0018.1, 2017.

Miyahara, M., Kanda, H., Yoshioka, T., and Okazaki, M.: Modeling Capillary Condensation in Cylindrical Nanopores: A Molecular Dynamics Study, Langmuir, 16, 4293-4299, https://doi.org/10.1021/la991227e, 2000.

Moore, E. B., de la Llave, E., Welke, K., Scherlis, D. A., and Molinero, V.: Freezing, melting and structure of ice in a hydrophilic nanopore, Phys. Chem. Chem. Phys., 12, 4124, https://doi.org/10.1039/b919724a, 2010.

Moore, E. B., Allen, J. T., and Molinero, V.: Liquid-Ice Coexistence below the Melting Temperature for Water Confined in Hydrophilic and Hydrophobic Nanopores, J. Phys. Chem. C, 116, 7507-7514, https://doi.org/10.1021/jp3012409, 2012.

Morishige, K. and Uematsu, H.: The proper structure of cubic ice confined in mesopores, J. Chem. Phys., 122, 044711, https://doi.org/10.1063/1.1836756, 2005.

Morishige, K., Yasunaga, H., and Uematsu, H.: Stability of Cubic Ice in Mesopores, J. Phys. Chem. C, 113, 3056-3061, https://doi.org/10.1021/jp8088935, 2009.

Mülmenstädt, J., Sourdeval, O., Delanoë, J., and Quaas, J.: Frequency of occurrence of rain from liquid-, mixed-, and ice-phase clouds derived from A-Train satellite retrievals: RAIN FROM LIQUID- AND ICE-PHASE CLOUDS, Geophys. Res. Lett., 42, 6502-6509, https://doi.org/10.1002/2015GL064604, 2015.

Murphy, D. M. and Koop, T.: Review of the vapour pressures of ice and supercooled water for atmospheric applications, Q. J. R. Meteor. Soc., 131, 1539-1565, https://doi.org/10.1256/qj.04.94, 2005.

Murray, B. J., L. Broadley, S., W. Wilson, T., J. Bull, S., H. Wills, R., K. Christenson, H., and J. Murray, E.: Kinetics of the homogeneous freezing of water, Phys. Chem. Chem. Phys., 12, 10380 10387, https://doi.org/10.1039/C003297B, 2010.

Muster, T. H., Prestidge, C. A., and Hayes, R. A.: Water adsorption kinetics and contact angles of silica particles, Colloid. Surface. A, 176, 253-266, 2001.

Nichman, L., Wolf, M., Davidovits, P., Onasch, T. B., Zhang, Y., Worsnop, D. R., Bhandari, J., Mazzoleni, C., and Cziczo, D. J.: Laboratory study of the heterogeneous ice nucleation on blackcarbon-containing aerosol, Atmos. Chem. Phys., 19, 1217512194, https://doi.org/10.5194/acp-19-12175-2019, 2019.

Pach, E. and Verdaguer, A.: Pores Dominate Ice Nucleation on Feldspars, J. Phys. Chem. C, 123, 20998-21004, https://doi.org/10.1021/acs.jpcc.9b05845, 2019.

Page, A. J. and Sear, R. P.: Heterogeneous Nucleation in and out of Pores, Phys. Rev. Lett., 97, https://doi.org/10.1103/PhysRevLett.97.065701, 2006.

Pedevilla, P., Fitzner, M., and Michaelides, A.: What makes a good descriptor for heterogeneous ice nucle- 
ation on OH-patterned surfaces, Phys. Rev. B, 96, 115441, https://doi.org/10.1103/PhysRevB.96.115441, 2017.

Pruppacher, H. R. and Klett, J. D.: Microphysics of Clouds and Precipitation, Kluwer Academic Publishers, Dordrecht, the Netherlands, 1997.

Riechers, B., Wittbracht, F., Hütten, A., and Koop, T.: The homogeneous ice nucleation rate of water droplets produced in a microfluidic device and the role of temperature uncertainty, Phys. Chem. Chem. Phys., 15, 5873, https://doi.org/10.1039/c3cp42437e, 2013.

Rogers, R. R. and Yau, M. K.: A short course in cloud physics, 3rd edn., Pergamon Press, Oxford., 1989.

Salazar, I. and Sepúlveda, L.: Nucleation of water by hydrophobic silicas, J. Colloid Interf. Sci., 94, 70-74, https://doi.org/10.1016/0021-9797(83)90235-7, 1983.

Schreiber, A., Ketelsen, I., and Findenegg, G. H.: Melting and freezing of water in ordered mesoporous silica materials, Phys. Chem. Chem. Phys., 3, 1185-1195, https://doi.org/10.1039/B010086M, 2001.

Seinfeld, J. H., Bretherton, C., Carslaw, K. S., Coe, H., DeMott, P. J., Dunlea, E. J., Feingold, G., Ghan, S., Guenther, A. B., Kahn, R., Kraucunas, I., Kreidenweis, S. M., Molina, M. J., Nenes, A., Penner, J. E., Prather, K. A., Ramanathan, V., Ramaswamy, V., Rasch, P. J., Ravishankara, A. R., Rosenfeld, D., Stephens, G., and Wood, R.: Improving our fundamental understanding of the role of aerosol-cloud interactions in the climate system, P. Natl. Acad. Sci. USA, 113, 5781-5790, https://doi.org/10.1073/pnas.1514043113, 2016.

Sing, K. S. W.: Reporting physisorption data for gas/solid systems with special reference to the determination of surface area and porosity (Recommendations 1984), Pure Appl. Chem., 57, 603619, https://doi.org/10.1351/pac198557040603, 2009.

Skrotzki, J., Connolly, P., Schnaiter, M., Saathoff, H., Möhler, O., Wagner, R., Niemand, M., Ebert, V., and Leisner, T.: The accommodation coefficient of water molecules on ice - cirrus cloud studies at the AIDA simulation chamber, Atmos. Chem. Phys., 13, 4451-4466, https://doi.org/10.5194/acp-134451-2013, 2013.
Stetzer, O., Baschek, B., Lüönd, F., and Lohmann, U.: The Zurich Ice Nucleation Chamber (ZINC)-A New Instrument to Investigate Atmospheric Ice Formation, Aerosol Sci. Tech., 42, 64-74, https://doi.org/10.1080/02786820701787944, 2008.

Thommes, M., Kaneko, K., Neimark, A. V., Olivier, J. P., Rodriguez-Reinoso, F., Rouquerol, J., and Sing, K. S. W.: Physisorption of gases, with special reference to the evaluation of surface area and pore size distribution (IUPAC Technical Report), Pure Appl. Chem., 87, 1051-1069, https://doi.org/10.1515/pac-2014-1117, 2015.

Umo, N. S., Wagner, R., Ullrich, R., Kiselev, A., Saathoff, H., Weidler, P. G., Cziczo, D. J., Leisner, T., and Möhler, O.: Enhanced ice nucleation activity of coal fly ash aerosol particles initiated by ice-filled pores, Atmos. Chem. Phys., 19, 8783-8800, https://doi.org/10.5194/acp-19-8783-2019, 2019.

Vali, G., DeMott, P. J., Möhler, O., and Whale, T. F.: Technical Note: A proposal for ice nucleation terminology, Atmos. Chem. Phys., 15, 10263-10270, https://doi.org/10.5194/acp-15-102632015, 2015.

Wagner, R., Kiselev, A., Möhler, O., Saathoff, H., and Steinke, I.: Pre-activation of ice-nucleating particles by the pore condensation and freezing mechanism, Atmos. Chem. Phys., 16, 20252042, https://doi.org/10.5194/acp-16-2025-2016, 2016.

Wang, B., Knopf, D. A., China, S., Arey, B. W., Harder, T. H., Gilles, M. K., and Laskin, A.: Direct observation of ice nucleation events on individual atmospheric particles, Phys. Chem. Chem. Phys., 18, 29721-29731, https://doi.org/10.1039/C6CP05253C, 2016.

Wang, J., Xue, H., Zhou, B., Yao, Y.-F., and Hansen, E. W.: Interfacial water in mesopores and its implications to the surface features - A solid state NMR study, Appl. Surf. Sci., 484, 11541160, https://doi.org/10.1016/j.apsusc.2019.04.095, 2019.

Zhuravlev, L. T.: The surface chemistry of amorphous silica. Zhuravlev model, Colloid. Surface. A, 173, 1-38, 2000.

Zobrist, B., Koop, T., Luo, B. P., Marcolli, C., and Peter, T.: Heterogeneous Ice Nucleation Rate Coefficient of Water Droplets Coated by a Nonadecanol Monolayer, J. Phys. Chem. C, 111, 2149-2155, https://doi.org/10.1021/jp066080w, 2007. 